\title{
New Guinean orogenic dynamics and biota evolution revealed using a custom geospatial analysis pipeline
}

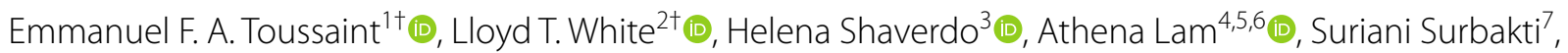
Rawati Panjaitan ${ }^{8}$, Bob Sumoked ${ }^{9}$, Thomas von Rintelen ${ }^{10} \mathbb{C}$, Katayo Sagata ${ }^{11}$ and Michael Balke $e^{4,12^{*}+}$ (D)

\begin{abstract}
Background: The New Guinean archipelago has been shaped by millions of years of plate tectonic activity combined with long-term fluctuations in climate and sea level. These processes combined with New Guinea's location at the tectonic junction between the Australian and Pacific plates are inherently linked to the evolution of its rich endemic biota. With the advent of molecular phylogenetics and an increasing amount of geological data, the field of New Guinean biogeography begins to be reinvigorated.

Results: We inferred a comprehensive dated molecular phylogeny of endemic diving beetles to test historical hypotheses pertaining to the evolution of the New Guinean biota. We used geospatial analysis techniques to compare our phylogenetic results with a newly developed geological terrane map of New Guinea as well as the altitudinal and geographic range of species (https://arcg.is/189zmz). Our divergence time estimations indicate a crown age (early diversification) for New Guinea Exocelina beetles in the mid-Miocene ca. $17 \mathrm{Ma}$, when the New Guinean orogeny was at an early stage. Geographic and geological ancestral state reconstructions suggest an origin of Exocelina ancestors on the eastern part of the New Guinean central range on basement rocks (with a shared affinity with the Australian Plate). Our results do not support the hypothesis of ancestors migrating to the northern margin of the Australian Plate from Pacific terranes that incrementally accreted to New Guinea over time. However, our analyses support to some extent a scenario in which Exocelina ancestors would have been able to colonize back and forth between the amalgamated Australian and Pacific terranes from the Miocene onwards. Our reconstructions also do not support an origin on ultramafic or ophiolite rocks that have been colonized much later in the evolution of the radiation. Macroevolutionary analyses do not support the hypothesis of heterogeneous diversification rates throughout the evolution of this radiation, suggesting instead a continuous slowdown in speciation.
\end{abstract}

Conclusions: Overall, our geospatial analysis approach to investigate the links between the location and evolution of New Guinea's biota with the underlying geology sheds a new light on the patterns and processes of lineage diversification in this exceedingly diverse region of the planet.

Keywords: Beetle evolution, Dytiscidae paleogeography, Island biogeography, Melanesia, Foja Gauttier Mountains, Ultramafic rocks, Water beetle phylogenetics

*Correspondence: balke.m@snsb.de

${ }^{\dagger}$ Emmanuel F. A. Toussaint, Lloyd T. White and Michael Balke have contributed equally to the study

${ }^{4}$ SNSB-Zoologische Staatssammlung München, Munich, Germany

Full list of author information is available at the end of the article

\section{Background}

New Guinea is the second largest island on Earth, featuring an exceedingly species rich biota, diverse climate zones and landforms [1], as well as a highly complex 

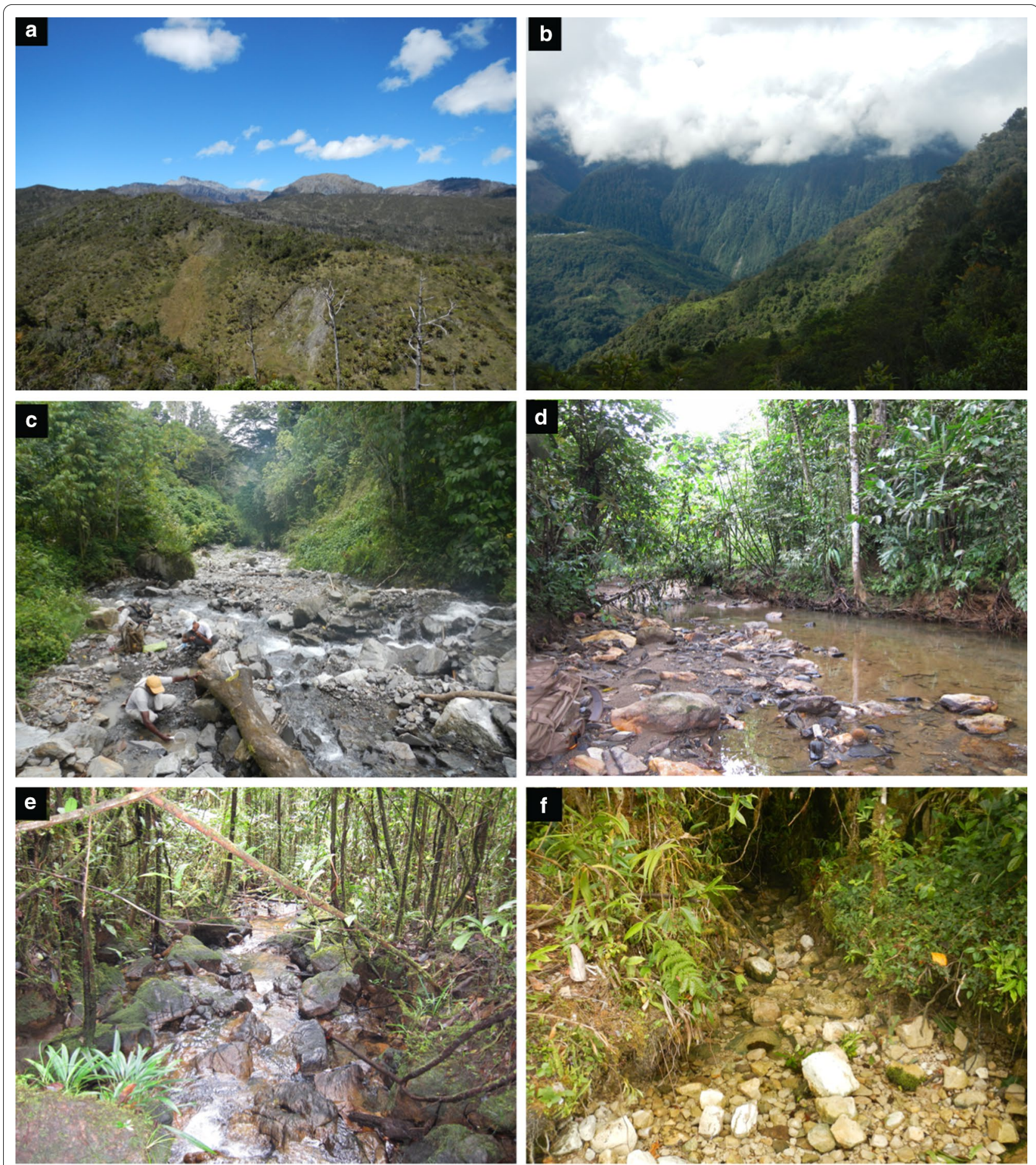

Fig. 1 Snapshot of landforms and habitat diversity of New Guinea. a High summits of the Central Range including Mount Trikora (Wilhelmina); b upper montane forest on the southern slopes of the Central Range below the summit region of Mount Mandala (Juliana); $\mathbf{c}$ montane forest at Syoubrig, Bird's Head, uplifted Australian Plate affinity rocks, 1,400 m; d lowland forest stream on Papuan Ophiolite Belt, south of Nabire, 340 m; $\mathbf{e}$ foothill forest stream on Papuan Ophiolite Belt, south of Nabire, 770 m; f creek in upper montane forest of Central Range, uplifted Australian Plate affinity rocks (Ok Sibil area). All photographs by M. Balke. 
(See figure on next page.)

Fig. 2 Geography of New Guinea and sampling localities. Custom build map using ArcGIS v10.4 and a comprehensive collection of geological maps described in the Methods section. The principal geological features are color-coded, see legend of Fig. 2 and Additional file 1 for further details. ARF (Arfak Mts), WEY (Weyland Mts), GT (Gauttier Terrane or Foja Mts), CM (Cyclops Mts), BW (Bewani Mts), TOR (Toricelli Mts), ADL (Adelbert Mts), FIN (Finisterre Mts), IOB (Irian Ophiolite Belt), POB (Papuan Ophiolite Belt). Sampling localities of the Exocelina individuals, dots colored according to the underlying geological terrane (lower panel)

geological history $[2,3]$ (Fig. 1). Yet, what we recognize as New Guinea with its present extent of $800,000 \mathrm{~km}^{2}$ and mountains as high as $4800 \mathrm{~m}$, only came about quite recently, most likely during the last few million years (Ma) of the planet's history (e.g., $[4,5])$. New Guinea would have looked much different in the past due to a combination of fluctuating global sea levels and various phases of tectonism which drove mountain building in some regions and subsidence in others [6]. For example, most of western New Guinea was submerged during the late Miocene-early Pliocene (i.e., 7-5 million years ago, Ma) [7]. These changing landscapes are primarily due to the fact that New Guinea marks the northern margin of the Australian Plate, and that it also marked the northern margin of Gondwana for hundreds of millions of years, prior to its break-up (e.g., [2, 3, 6, 8-10]). This zone of interaction between tectonic plates implies that pieces of Earth's crust have been progressively added to the island, as well as being torn from the island and laterally transported from west to east along large-scale faults over a long period of time (e.g., [6, 11-15]). This history is reflected in the rocks found on New Guinea today. Regions that share a similar age, history and affinity can be mapped and classified as a "terrane" (Fig. 2).

Increasingly detailed paleogeographic reconstructions and the availability of larger scale molecular phylogenetic analyses have created an opportunity to empirically investigate biodiversity patterns and processes, and possibly relate them to geological change. For instance, [7] used fossilized benthic foraminifera assemblages and geological data to reconstruct relative sea-level changes of the western New Guinea area (including the Bird's Head Peninsula, Fig. 2). They show how paleodepositional environments changed through time. While the inference of areas above sea-level and regions of poor data coverage remains tentative, their evidence suggests a strongly varying configuration of land and sea in the region since the Carboniferous, with possible submergence of the entire region from the middle Miocene until a period of rapid uplift in the late Pliocene-Pleistocene. This work, together with other geological studies, indicates that the uplift and formation of the present-day, rugged, west New Guinea landscape is due to recent tectonism associated with the interaction between the Australian and Pacific plates, primarily during the past $5 \mathrm{Ma}$ (e.g., $[4,13,16-20])$. These paleogeographic models have found an unexpected echo in recent empirical evolutionary studies. For instance, a population genomic study of a diving beetle species with a wide range across the Bird's Head suggests that the strong geographic structure found could possibly be related to the area's fairly recent fluctuations in land/sea configuration [21].

A series of recent papers on different groups of animals (e.g., [13, 21-40]; summaries in [33] and [41]) and plants (see e.g., [42] and references therein) identifies three major processes fueling biological diversification in New Guinea: (1) ancient diversification events on smaller proto Papuan islands including a proto Papuan Peninsula, or on the northern part of the Australian craton (see [27, 33, 43-45]), (2) more recent but substantial lineage diversification connected to the New Guinea orogeny (e.g., $[41,46])$, or (3) formation of land in the north and south of the central highlands by various processes (volcanism, accretion/uplift of island arcs and ophiolites). The latter includes complex phylogeographic processes across the New Guinea lowland rainforest belts that led to the formation of allopatric species pairs (e.g., crowned pigeons: [47]) and orogeny related vicariance [48] (see Table 4).

In a series of innovative papers, biogeographers sought to directly link distribution patterns to such geological events, strongly motivating increased exchange between biologists and geologists over the past two decades (e.g., $[39,41,49-52])$. This is certainly the case to a large extent, but many clade diversification events might also result from biotic exchange across a more or less existing landmass, although composite and gaining altitude, as suggested by few recent analyses of insects [26, 41], frogs [32] and birds [25, 29, 47]. In that case, and related to the above process (3), the extant geography of the island might be structuring clades of species more than the geological formation on which they occur (see [41]).

In the broadest geological sense, New Guinea can be broken down into three terranes (Fig. 2).

1. Most of the northern coastline ("northern belt") consists of rocks that were once part of the Pacific Plate and were pushed southward, onto the New Guinea margin (e.g., [6, 11, 12]) ("Accreted Pacific" and "Mesozoic ultramafic rocks" in our analyses, Table 1). The "Accreted Pacific" terranes contain segments of volcanic arcs that were part of the Pacific Plate during the Eocene-Miocene. The "Mesozoic ultramafic 


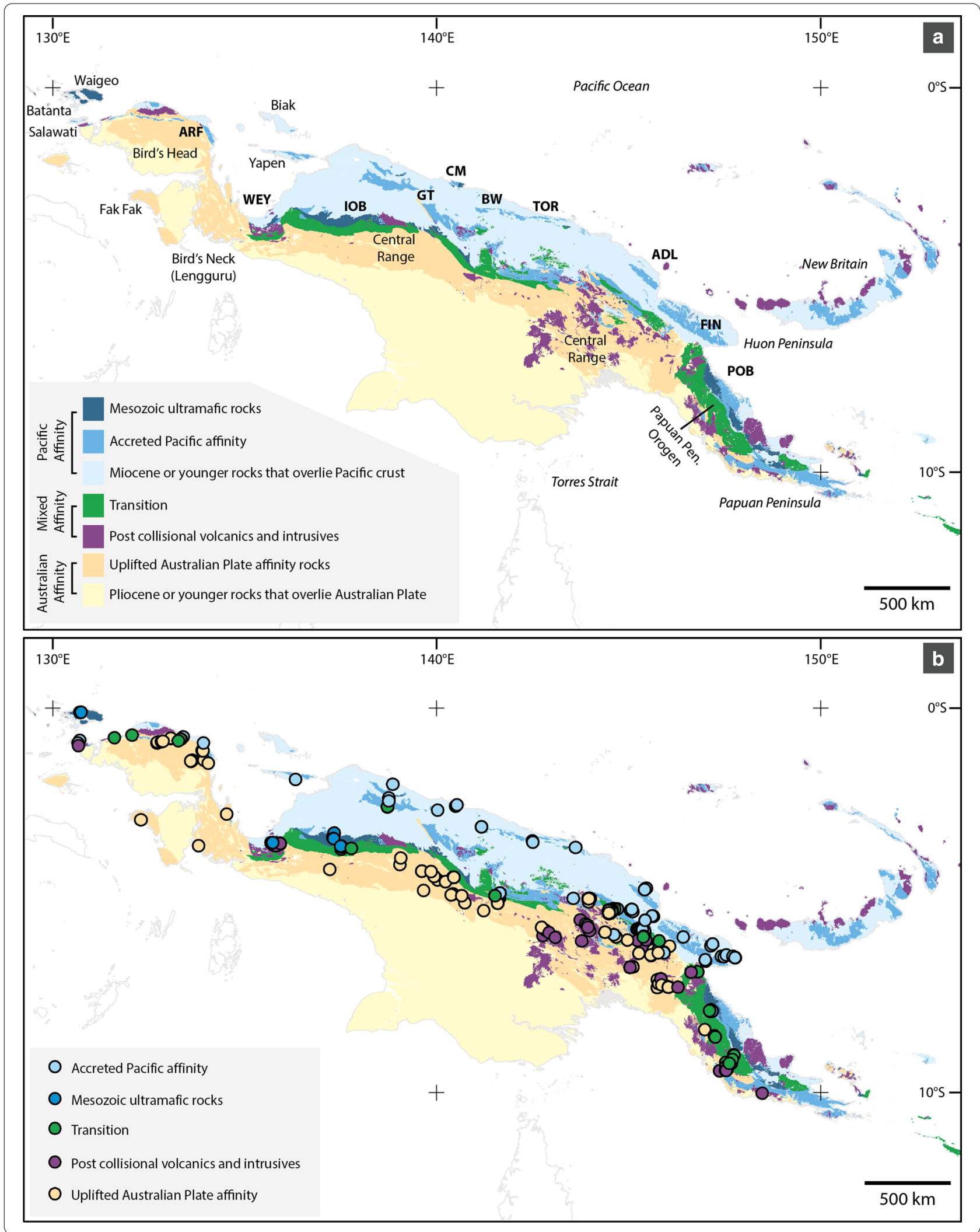


Table 1 Explanation of the scheme that was used to classify particular regions of the geological map to a particular terrane

\begin{tabular}{|c|c|}
\hline Geological terrane & Description \\
\hline Uplifted Australian Plate affinity & $\begin{array}{l}\text { Rocks that are Miocene or older and have always been or were once part of the Australian } \\
\text { Plate }\end{array}$ \\
\hline Transitional & $\begin{array}{l}\text { Metamorphic rocks - typically of Cretaceous age. Note however, these typically have } \\
\text { poor age control and more often than not were classified on the basis that these are } \\
\text { deformed/metamorphic rock }\end{array}$ \\
\hline Mesozoic ultramafic rocks & Refers to Cretaceous or older ultramafic rocks \\
\hline Accreted Pacific Plate affinity & $\begin{array}{l}\text { Cretaceous to Early Miocene mafic volcanic rocks that likely accreted to New Guinea's } \\
\text { northern margin during the Cretaceous, or during the Eocene-Oligocene. This classifica- } \\
\text { tion contains some ultramafic rock }\end{array}$ \\
\hline Post collisional volcanics and intrusives & Refers to volcanic and plutonic rocks that are Miocene age or younger \\
\hline Miocene or younger rocks that overlie Pacific Plate & $\begin{array}{l}\text { Refers to sedimentary rocks and carbonates that are Miocene or younger that overlie what } \\
\text { was once likely part of the Pacific Plate (and therefore assumed to also be representative } \\
\text { of the 'Accreted Pacific Plate affinity' category) }\end{array}$ \\
\hline Pliocene or younger rocks that overlie the Australian Plate & $\begin{array}{l}\text { Refers to sedimentary rocks and carbonates that are Pliocene or younger that overlie what } \\
\text { is or was once part of the Australian Plate (and therefore assumed to also be representa- } \\
\text { tive of the 'Uplifted Australian Plate affinity' category) }\end{array}$ \\
\hline
\end{tabular}

rocks" represent areas where sections of Cretaceous and older seafloor have been uplifted and pushed onto northern New Guinea (i.e., ophiolites) (e.g., [3, $14,53,54])$.

2. Much of the Bird's Head Peninsula, the Central Range, parts of the Owen Stanley Range (Papuan Peninsula), and the region to the south of this mountain belt all comprise rocks that were once part of Gondwana with many being compositionally and age equivalent to rocks found in northern Australia (e.g., $[8,9,55]$ ) ("Uplifted Australian Plate affinity rocks" in our analyses, Table 1 ).

3. Between these two zones is a 'transition zone' (or transition belt) where there is a mixture of deformed rocks of Pacific and Australian plate affinities that have been tectonically juxtaposed [56, 57] ("Transition" in our analyses). There are also small areas of volcanic and intrusive rocks that erupted or were emplaced after plate collision ("Post collisional volcanics and intrusives" in our analyses). These igneous rocks are relatively young and typically occur as small regions within the other terranes (Table 1). Readers should note that the "Post collisional volcanics and intrusive rocks" are not related to the arc volcanic/ accreted Pacific material.

The juxtaposition of ancient Australian Plate rocks with younger volcanic arcs and sections of ocean floor provide a first-order control on New Guinea's unique biogeography $[28,33,41,42,50,51]$.

Here, we aim at reviewing the idea of geology-driven lineage diversification, using a newly assembled terrane framework that outlines the distribution of the major geological features of New Guinea according to the current state of geological knowledge (Fig. 1). The material and methods section provides a detailed account on the geological and biogeographic background.

Three major historical hypotheses can be formulated. $H 1$ is diversification on ancient islands arcs that make up the present day north coast ranges since the midMiocene or earlier [33, 43], and related to that $H 1 A$ that colonization of the little studied Foja Mountains occurred around that time. Hypothesis $H 2$ is that older clades should occur in, or nearby, areas of ophiolite and ultramafic rocks (e.g., Mesozoic ultramafic rocks, Fig. 2; see e.g. [58]).

With focus on the vast Central Range of New Guinea, our hypothesis $H 3$ suggests an early diversification, possibly in an initial setting of a chain of islands, and subsequent colonization of surrounding areas such as the Bird's Head and the Papuan Peninsula. More specific tests could be made under the following assumptions: (hypothesis H3A) the $1300 \mathrm{~km}$ long Central Range initially consisted of several islands, this implies localized radiations in different present-day highland blocks; (hypothesis $H 3 B$ ) there is a temporal sequence from west to the east; (hypothesis $\mathrm{H3C}$ ) mountains of eastern PNG, the Papuan Peninsula, have existed as a separate island before $25 \mathrm{Ma}$ and do therefore harbor fauna older than expected based on the above geological scenarios, and served as source area for other parts of New Guinea.

Furthermore, we investigate the role of geography in structuring clades by asking if geographic structure of extant clades is caused by geological history or more recent processes.

In order to test these hypotheses, we use geospatial analysis techniques to compare the results of a 


\section{(See figure on next page.)}

Fig. 3 Bayesian divergence time estimates of Exocelina diving beetles. Chronogram presenting median ages across New Guinean Exocelina derived from the best BEAST analyses based on MLE comparisons (12 uncorrelated lognormal relaxed clocks with a birth-death tree model). 95\% credibility intervals are given in purple horizontal rectangles. Branch support derived from the best IQ-TREE ML tree search is given (SH-aLRT/UFBoot). A

summary of the BAMM analyses is inserted in the bottom left corner of the figure showing a decrease in speciation rate through time.

comprehensive molecular phylogeny of New Guinea Exocelina diving beetles (Coleoptera, Dytiscidae, Copelatinae) with the location, altitude and underlying geology of where each beetle was sampled. These beetles have recently been developed as a fruitful study system to investigate fine to large-scale patterns of evolution across New Guinea and also Melanesia [21, 41, 46, 59, 60]. Greatly benefiting from repeated collecting campaigns combined with fast integrative taxonomy, knowledge of this genus has steadily increased over the past few years. To date, 152 species have been described from New Guinea and its satellite islands (e.g., [61, 62]), 151 of which form a monophyletic group (see [41, 46]. The majority of species outside New Guinea occur in Australia and New Caledonia, with single species e.g., in Hawaii, China, Peninsula Malaysia [63] and Vanuatu. Most species are found in a variety of running water associated habitats (but avoiding water current), only a few Australian and only one New Guinea and New Caledonian species, respectively, inhabit pools or swamps [46]. For the New Guinea radiation, typical habitats include small stagnant water bodies on riverbanks, the interstitial, water filled rock holes in stream beds, or the tiniest wet spots beside creeks, or even above what most people perceive as the actual spring. The beetles are carnivorous, and as far as known, prey on virtually anything they can, including pieces of fish that were placed as a bait (M. Balke, unpublished). Feeding preferences remain unknown. Larvae have not been found to date, suggesting a rather hidden or unusual way of life. Exocelina diving beetles would preferably hide in gravel, among pebbles or underneath leaves (Fig. 1). In New Guinea, they occur from close to sea level up to $3000 \mathrm{~m}$ altitude (https://arcg.is $/ 189 \mathrm{zmz}$ ). The beetles are capable of flight, yet most species have small ranges. A few are comparably widespread, according to species delineated based on morphological characters (e.g., [64]. Phylogenomic data did nevertheless reveal extreme levels of very recent geographic population differentiation in one supposedly widespread species [21]. Such differentiation occurred between sites as close as $40 \mathrm{~km}$, with no obvious major landscape obstacles. While the beetles can fly, it remains to be tested empirically which flight pattern they show and how far they fly-flight might for example only occur along a particular creek or river bed until the next suitable spot was reached. Lam et al. [21] suggested that dispersal might be rare, and possibly limited by barriers such as marine intrusions, but again, this remains to be tested.

However, being lotic taxa with the above properties known, as well as being easily detected in the field, suggested Exocelina as a feasible group to study across a vast area.

\section{Results \\ Geospatial data}

All our data, the terrane map and the regional classification are summarized in an online platform at https:// arcg.is/189zmz.

\section{Phylogenetic inference and node age estimation (Fig. 3)}

The results of the best scoring IQ-TREE ML search are presented in detail in Additional file 1: Appendices 5, 6 . The topology for the monophyletic New Guinean radiation $(\mathrm{SH}-\mathrm{aLRT}=100 / \mathrm{UFBoot}=100)$ is presented in Fig. 3 along with the results of the best BEAST analysis (Table 2). All dating analyses conducted in BEAST converged well as indicated by high ESS values $(>200)$ for all estimated parameters. The comparison of MLE suggests that the analysis including 12 clocks and a birthdeath model is the best fit (Table 2), and therefore we present the results of this analysis in Fig. 3 (see also Additional file 1: Appendices 7, 8). The crown of Copelatinae is dated back to $c a$. $92 \mathrm{Ma}$ (95\% credibility interval 76-110 Ma). The split between the crown of Exocelina (46 Ma, 95\% CI37-56 Ma) and the crown of Liopterus and Capelatus (67 Ma, 95\% CI 46-88 Ma) is dated back to $c a$. $77 \mathrm{Ma}$ (95\% CI59-98 Ma). The split between the New Guinean radiation (17 Ma, 95\% CI14-21 Ma) and its sister clade of Australian subterranean species (24 Ma, 95\% CI 16-32 Ma) is dated back to ca. $32 \mathrm{Ma}(95 \%$ CI 25-39 Ma).

\section{Patterns identified using geospatial analytical technique}

Each value within the sample database (Additional file 1: Appendix 2) was classified into one of five groups according to the output of the ArcGIS Grouping Analysis tool (Additional file 1: Appendix 9). These results have been drawn as a series of maps (Additional file 1: Appendix 9) and were plotted as a series of 2D histogram "heat maps" (Additional file 1: Appendix 10). Group 1 consists of samples collected from regions that are $<500 \mathrm{~m}$ altitude 


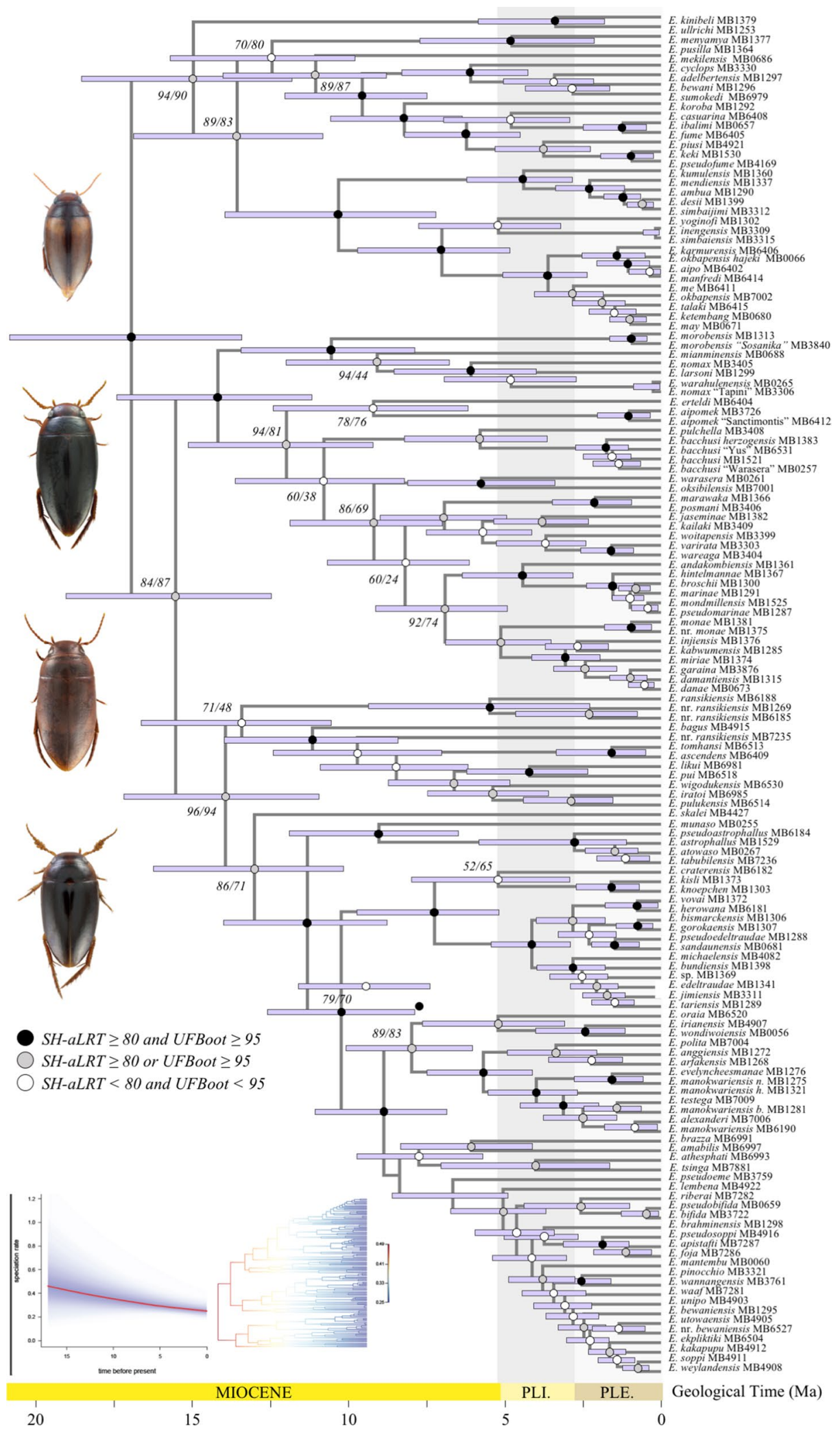


Table 2 Comparison of BEAST analyses using marginal likelihood estimates

\begin{tabular}{|c|c|c|c|c|c|c|c|}
\hline Analysis & Clocks & Tree model & SS MLE & PS MLE & Crown Copelatinae & Crown Exocelina & Crown NG Exocelina \\
\hline $\mathrm{A} 1$ & 2 & Yule & -68127.998 & -68127.821 & $100.16(81.05-116.80)$ & $49.31(38.41-60.43)$ & $20.57(14.28-23.07)$ \\
\hline$A 2$ & 2 & Birth death & -68096.052 & -68096.531 & $92.84(74.25-111.88)$ & $39.16(29.93-49.40)$ & $14.78(11.15-18.79)$ \\
\hline A3 & 12 & Yule & -67442.242 & -67437.208 & $99.39(82.36-116.47)$ & $53.88(43.43-63.25)$ & $20.97(16.84-25.22)$ \\
\hline A4 & 12 & Birth death & -67417.937 & -67414.115 & $92.63(75.59-110.38)$ & $46.00(37.19-55.83)$ & $17.06(13.53-20.98)$ \\
\hline
\end{tabular}

and dominantly Accreted Pacific Plate affinity. Group 2 broadly consists of values that reside on Accreted Pacific Plate affinity rocks, and altitudes between $500 \mathrm{~m}$ and $3500 \mathrm{~m}$. Group 3 broadly consists of sites that reside on dominantly Transitional zone rocks (as well as some postcollisional igneous rocks) at altitudes of $0 \mathrm{~m}$ to $1500 \mathrm{~m}$. Group 4 consists of samples collected from regions of dominantly Australian Plate affinity, as well as at altitudes of $<1500 \mathrm{~m}$. Group 5 consists of sample sites $>1500 \mathrm{~m}$, and from a mixture of rock types (mostly Accreted Australian Plate affinity as well as ultramafics and post collisional igneous rocks).

\section{Ancestral state reconstructions}

The output files from the BMM analyses are provided in the supplement, including additional trees detailing the node distributions (Additional file 1: Appendix 11). For clarity, Figs. 4 and 5 only show the most likely states (MLS) at the nodes.

\section{Geology (Fig. 4)}

From the first node of the tree (node 1) and along its entire backbone (e.g., nodes 8, 13, 18, 19, 21, 24, 29), we almost unambiguously infer presence on geological formations with Uplifted Australian Plate affinity as the ancestral state (MLS node 1: E, prob. 0.984; others CE, 0.003, AE 0.009). This translates to occurrence on or along the orogenes of the Bird's Head, the Central Ranges as well as the Papuan Peninsula (see also Fig. 6, geography). From $c a$. $10 \mathrm{Ma}$, we find clear evidence for some degree of species level diversification in the Transition areas ("coded as D) along the northern margins of the mountains as well as the interwoven post collisional volcanics and intrusives ("C"), e.g., at node 10 (MLS: D, prob. 0.291; followed by C, prob. 0.259). At approximately the same time, in a clade containing species from the Papuan Peninsula, the north coast ranges as well as the Central Range, we find increased interactions with these areas C and D (node 11, MLS: CE, prob. 0.207; E, prob. 0.222 ; C, prob. 0.148), followed by a number of nodes with ambiguous states but including $\mathrm{C}$ and or $\mathrm{D}$ (at node 7, this was estimated at ca. 5 Ma (MLS: C, prob. $0.758)$.
Interactions with the Pacific accreted/younger overlying rocks (area A), might have occurred early on, with some ambiguity, from ca. 12-10 Ma (node 4), less ambiguously so from $c a$. 6 Ma with a clade with species from the Cyclops, Adelbert and Bewani Mts as well as the foothills of the Central Range West (node 5). In that clade, we also found two species on the Pacific Mesozoic ultramafics (Ophiolite), one in the Cyclops Mts and one in the foothills of the Central Range West. Species on the Pacific Mesozoic ultramafics also occur more towards the tip nodes across the tree (see Fig. 4, obduction pictograms above tree terminals). At $c a$. $11 \mathrm{Ma}$, at node 16, we find the oldest shift from Australian Plate to the Pacific Plate/Mesozoic ultramafics (MLS: B, prob. 0.829; E prob. 0.786; BE prob. 0.725), these are species from the Irian Ophiolite Belt (IOB) as well as the species E. bagus in Mt. Gamey area in the foothills north of the Weyland Mts. Exocelina bagus is the sister to rest of the clade at node 16 (thus dated at $11 \mathrm{Ma}$ ). The wider Mt. Gamey area (north of the Weyland Mts) also has a number of species in the clade above node 33 assigned to $\mathrm{B}$, ultramafics, but with more recent presence there, starting $<3 \mathrm{Ma}$.

The geological distribution of each taxon is also visualized in a 2D histogram "heat map" and plotted onto the phylogenetic tree in Additional file 1: Appendix 10.

\section{Geography (Fig. 5)}

The MLS at the first node (node 1) was F, occurrence in the Central Range East (probability 0.838), followed by C, Papuan Peninsula (0.053). The clade at node 2 also had MLS F (0.991, or EF, 0.004). In that clade, starting at $c a$. $15 \mathrm{Ma}$, species diversified in the eastern bloc of the Central Range in PNG, and from there from ca. 12-10 Ma in the north coast ranges (area A, e.g., node 4). From ca. $3 \mathrm{Ma}$ we infer exchange from the north coast ranges towards the western part of the Central Range (clade 5). There is repeated interaction with the central part of the Central Range (E, Star Mountains), which from ca. $4 \mathrm{Ma}$ also show a local radiation (in the clade above node 6).

The ancestral state reconstruction for the next major node (node 8 ) suggests the MLS being F (0.656), followed by $C$ (0.139), suggesting occurrence in either the Central Range East, or Papuan Peninsula. The clade at node 9 (MLS C), containing most of the species from 


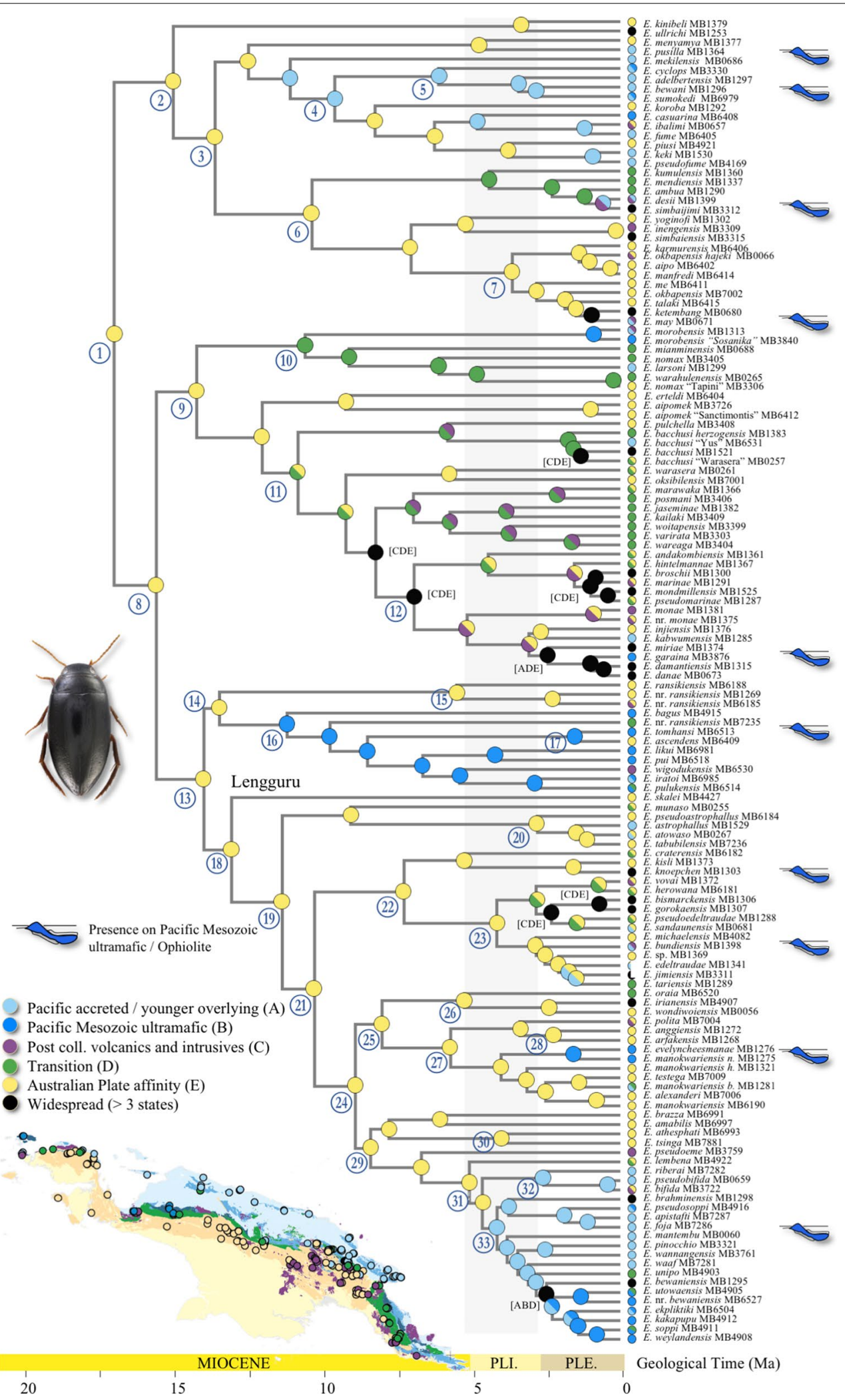

Fig. 4 Maximum likelihood ancestral state estimation for geology coding 


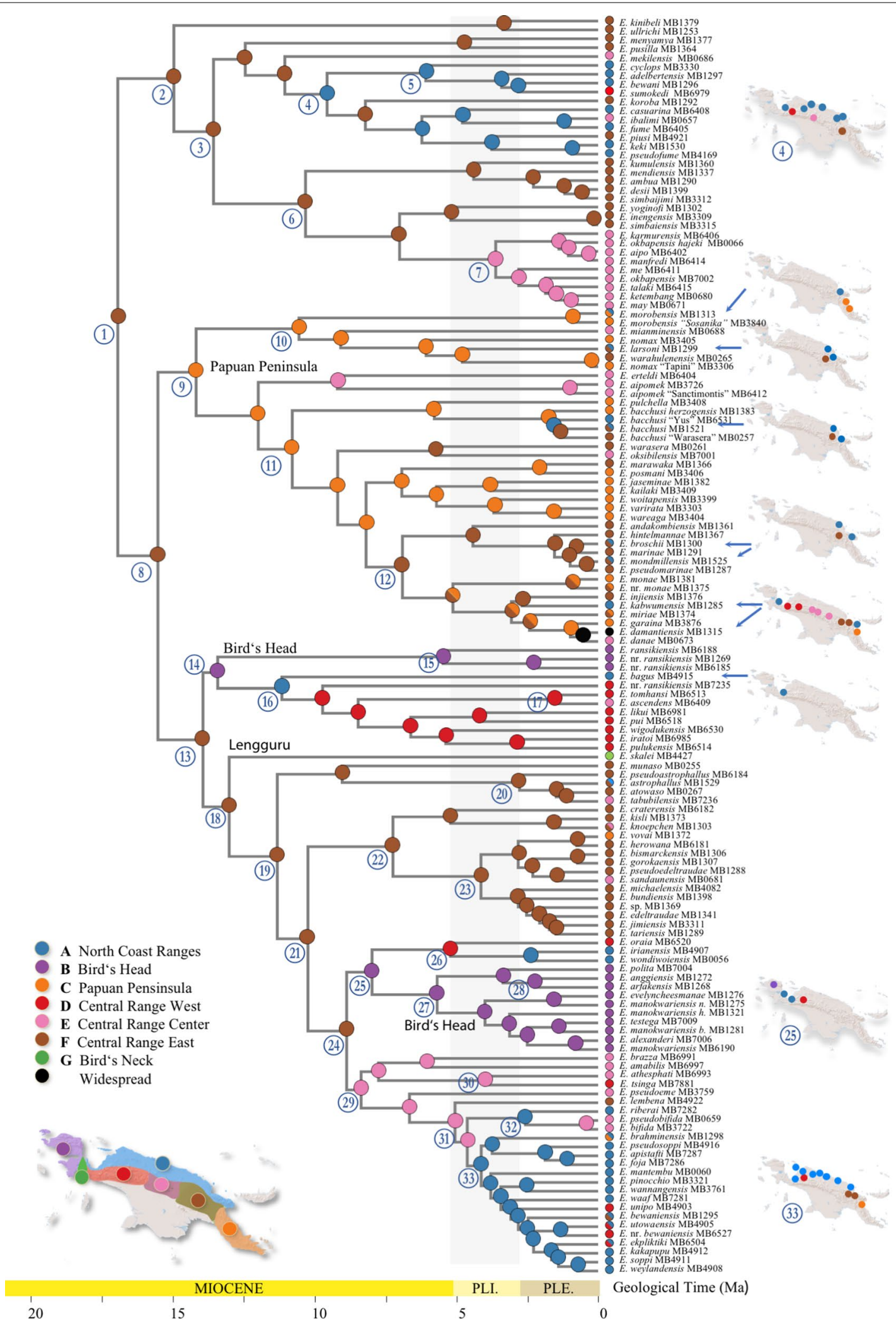

Fig. 5 Maximum likelihood ancestral state estimation for geography coding. Inlay map shows the regions coded for the analysis, numbered nodes are discussed in the text; the maps to the right of the terminals visualize the distribution of a single species (one arrow) or a clade of species (two arrows or node number), the dot color corresponds to color code of geographic area. 

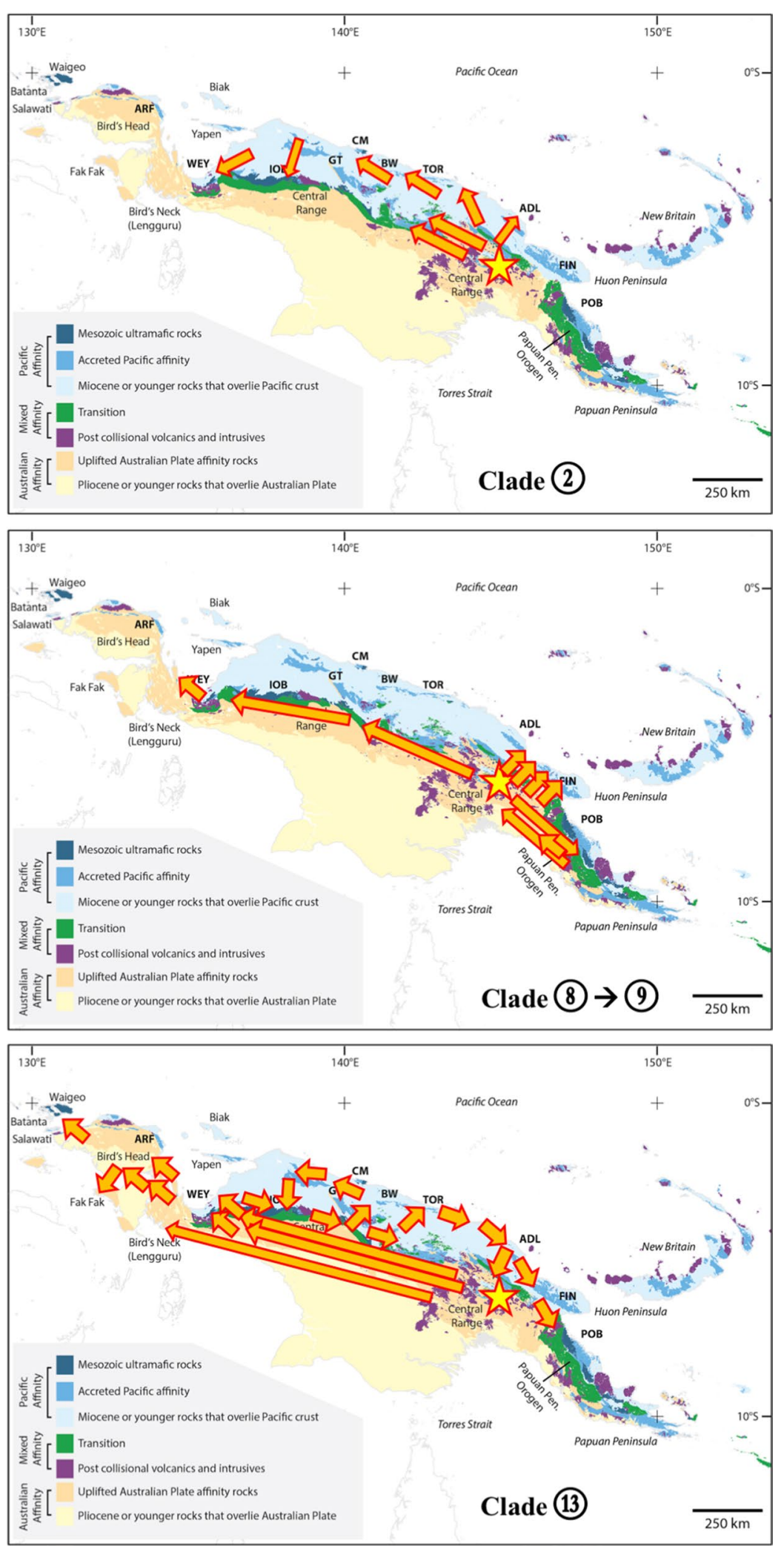

Fig. 6 Graphical summary of major biogeographic processes inferred in the present paper. Note, the length and position of arrows indicates simplified processes, length and direction generalized 
the Papuan Peninsula, is comparably dynamic in terms of geographic distribution, with interactions with areas $\mathrm{A}, \mathrm{D}, \mathrm{E}$ and $\mathrm{F}$. The rather unambiguous diversification in the Papuan Peninsula was inferred from $c a$. $14 \mathrm{Ma}$. From there, we find interaction with neighboring north coast ranges (e.g., Huon, Adelbert and S of Madang), and the Central Range from the east towards the west into Indonesian Papua. One recent species, $E$. damantiensis $(<3 \mathrm{Ma})$ is widespread across the island (ACDEF) (in clade 12).

Moving up the tree backbone, nodes 13, 18, 19, 21 and 24 have the same MLS: F, Central Range East. Major transitions occur ca. 13 Ma towards Bird's Head and Central Range West (nodes 14, 16), and the Bird's Neck (Lengguru, at node 18). The single species sampled from the Bird's Neck (Lengguru) region, E. skalei, is therefore rather isolated and separated from its species rich sister clade $c a .13 \mathrm{Ma}$ (node 18). Later, at $c a$. $9 \mathrm{Ma}$, there are transitions to E, Central Range Center (node 29), and the Bird's Head and adjacent areas (node 25) (see below).

From node 13, diversification events appear well structured geographically. The clade at node 14 has a subclade with three Bird's Head species, and one clade (node 16) mainly with species from the Central Range West (MLS A or D). This clade contains one species from neighboring north coast ranges (A, Exocelina bagus) and one from Central Range East (E, Exocelina ascendens, which is similar genetically and morphologically to $E$. tomhansi in area D) (node 17). At node 18, branches off one species from the Bird's Neck or Lengguru extension of the Bird's Head, sister to a clade at node 19 with MLS F (prob. 0.907), with local species diversification locally structured according to areas A, B, E and F. The clade at node 25 (MLS: B, prob. 0.623) contains species from the Bird's Head region as well as three species coded A or D, however, from localities in close proximity to region "B". The clade at node 29 (MLS: E, prob. 0.946) has species mainly in the Central Range Center (few in East or West). From there, at node 33 (MLS: A, prob. 0.858), we infer a range expansion into the north coast ranges, at the end of the Miocene, with species along the north coast including in Indonesia: Yapen Island, Weyland Mts foothills south of Nabire, Van Rees Mts, the Foja Mountains, and in PNG the Bewani, Toricelli, Adelbert and Herzog Mts. That range expansion was roughly out of Central Range east towards the north coast and then occurred in a roughly westward direction up to Yapen Island and the area south of opposite Nabire, which is especially species rich with at least 10 species originating in the past ca. $5 \mathrm{Ma}$.

Actual diversification in the Bird's Head region and satellite islands Waigeo, Batanta and Salawatti began between $c a$. 9-6 Ma (nodes 15, 25), possibly older $c a$.
14 $\mathrm{Ma}$ (if species at node nodes 14 already occurred in the Bird's Head region).

ed.

\section{Diversification rate dynamics estimation}

The different BAMM analyses performed on the chronogram corresponding to the New Guinean radiation yields identical results. We recovered a scenario with no rate heterogeneity among New Guinean clades. Regardless of the number of expected shifts, the analysis of parameter posterior distributions recovered a single most credible shift configuration with no rate shift throughout the evolution of the New Guinean radiation. The phylorate summary analyses and rate through time plots suggested a continuously declining speciation rate through time. We present the results of the analysis with an expected number of shifts of 0.1 in Additional file 1: Appendix 13.

The RPANDA analyses recovered a model with both speciation and extinction rates varying linearly with time (BTimeVarDTimeVar_LIN, LnL $=-352,770$ ) as the bestfit model for the evolution of New Guinean Exocelina. This model was a significantly better fit than other timedependent and diversity-dependent models. The latter all indicated that the New Guinean Exocelina radiation is still far from its potential carrying-capacity (parameter $\mathrm{K}$ in Table 3). The preferred model recovered a slowdown of both speciation and extinction rates through time (Table 3).

\section{Discussion}

\section{Phylogenetic inference, divergence} times and diversification dynamics

Within Exocelina, our topology slightly differs from earlier studies based on overlapping but more reduced molecular datasets $[41,65]$, they are however largely consistent with the latest placement of the genus [46] in Copelatinae (see Additional file 1: Appendix 5). Our results recover three main clades (2, 9 and 13). The monophyly of these lineages and their relationships are strongly to moderately supported, representing substantial progress in the establishment of a robust evolutionary tree for the genus Exocelina. Several morphological species-groups (MSG) appear paraphyletic or polyphyletic suggesting the need for a revision of species-group composition and key synapomorphic characters. The largest MSG is the E. ekari group, here recovered at node 18.

In terms of divergence times, our estimates shed a new light on Exocelina evolution, with contrasting results from earlier studies. Here, we estimated the crown age of New Guinean Exocelina ca. $17 \mathrm{Ma}$, previous studies suggested ca. $5 \mathrm{Ma}$ (3.74-7.07 Ma) [46] or $9 \mathrm{Ma}$ (5.51$12.50 \mathrm{Ma})$ in [41]. 
Table 3 Results the diversification analyses conducted on the New Guinean Exocelina radiation

\begin{tabular}{|c|c|c|c|c|c|c|c|c|c|}
\hline Model & Param, & Log Likelihood & $\mathrm{AlCc}$ & $\triangle \mathrm{AlC}$ & $\lambda$ & $a$ & $\mu$ & $\beta$ & K \\
\hline BCST & 1 & $-358,847$ & 719,723 & 5,892 & 0,2405 & - & - & - & - \\
\hline BCSTDCST & 2 & $-358,847$ & 721,780 & 7,949 & 0,2405 & - & 0 & - & - \\
\hline BTimeVar_EXPO & 2 & $-358,584$ & 721,254 & 7,423 & 0,2241 & 0,01626 & - & - & - \\
\hline BTimeVarDCST_EXPO & 3 & $-358,584$ & 723,342 & 9,511 & 0,224 & 0,01629 & 0 & - & - \\
\hline BCSTDTimeVar_EXPO & 3 & $-358,847$ & 723,868 & 10,037 & 0,2405 & - & 0 & 0,012 & - \\
\hline BTimeVarDTimeVar_EXPO & 4 & $-358,584$ & 725,460 & 11,629 & 0,2241 & 0,01628 & 0 & 0,03216 & - \\
\hline BTimeVar_LIN & 2 & $-358,634$ & 721,355 & 7,524 & 0,2236 & 0,00395 & NA & - & - \\
\hline BTimeVarDCST_LIN & 3 & $-358,634$ & 723,442 & 9,611 & 0,2235 & 0,00396 & 0 & - & - \\
\hline BCSTDTimeVar_LIN & 3 & $-358,891$ & 723,955 & 10,124 & 0,2402 & - & 0 & 0 & - \\
\hline BTimeVarDTimeVar_LIN & 4 & $-352,770$ & 713,831 & - & 0,0138 & 0,46044 & 0,35132 & 0,40155 & - \\
\hline DDL & 2 & -358.622 & 721.331 & 7.5 & 0.273 & - & - & - & 786.86 \\
\hline $\mathrm{DDL}+\mathrm{E}$ & 3 & -358.526 & 723.226 & 9,395 & 0.3614 & - & 0.07543 & - & 375.61 \\
\hline $\mathrm{DDX}+\mathrm{E}$ & 3 & -358.578 & 723.329 & 9,498 & 0.5011 & - & 0.0474 & - & Inf \\
\hline $\mathrm{DDL}+\mathrm{EL}$ & 4 & -358.532 & 725.355 & 11,524 & 0.3391 & - & 0.05839 & - & 426.98 \\
\hline
\end{tabular}

Param number of parameters in each model, $\triangle A I C C$ the difference of AICc between any model and the best scoring model (i.e., BTimeVarDTimeVar_LIN), $\lambda$ speciation rate at present, $a$ dependency of speciation rate on time time (positive value indicates a slowdown of speciation rate, negative value indicates an acceleration of speciation rate), $\mu$ extinction rate at present, $\beta$ dependency of extinction rate on time (positive value indicates a slowdown of extinction rate, negative value indicated an acceleration of extinction rate), $K$ carrying capacity (species richness) estimated for diversity-dependent models

These observed discrepancies are largely due to the methodology used to obtain absolute divergence times using molecular clock calibrations. Earlier studies mostly relied on beetle rates of evolution or fossil calibrations placed in the outgroups, while the current one relies on secondary calibrations applied across a large selection of lineages and derived from a robust fossil-based evolutionary framework of diving beetles [66]. Hence, we believe these new estimates to be much more in line with the evolutionary history of these diving beetles than earlier estimates. Based on these new estimates, we infer that the three main clades 2, 9 and 13 diverged in the mid-Miocene $c a .15 \mathrm{Ma}$. The rest of diversification was gradual up to the last million years within the Pleistocene.

This is confirmed by BAMM analyses suggesting a diversification regime with no rate shifts and a continuously declining speciation rate through time. Our RPANDA analyses across the entire New Guinean radiation confirm this result with the best-fit model suggesting declining speciation and extinction through time (Table 3). This diversification rate regime was already suggested by [46] who analyzed the role of island colonization on diversification rate regimes in Exocelina. The authors showed that a significant increase in diversification rates occurred as soon as (proto) New Guinea was colonized and that this early burst in diversification was followed by a slow but steady decrease in speciation rates through time. This pattern substantiated here with a more extensive taxon sampling and different methods invalidates the hypothesis of diversity being bound by the availability of suitable habitat as suggested in [46]. Our DDD analyses recover a carrying-capacity that is far greater than the current and expected species richness in Exocelina. As a result, the declining diversification rate in Exocelina appears to be disconnected from diversitydependent processes. The diversification dynamics in New Guinean Exocelina follows a model with an early burst in diversification coinciding with the colonization of New Guinea emergent landmasses out of Australia, followed by a progressively declining diversification pace. Though many processes may be responsible, competition possibly drove body size segregation in at least one instance. On lower elevations, species of the closely related genus Copelatus commonly occupy the same microhabitat as Exocelina. With Copelatus species being larger than Exocelina, competition between the two in sympatry may limit the potential number of Exocelina species in such habitats [46]. However, this remains to be tested with additional data, and thus, our results need to be carefully interpreted in light of the current debate regarding the potential pitfalls when estimating diversification rate dynamics from extant phylogenies [67].

Diversification processes are lineage idiosyncratic per se. Another pattern is, for example, a slight increase of diversification rates possibly related to the colonization of newly emerging landmasses in the proto Papuan archipelago. This was suggested for microhylid frogs, with an inferred temporal sequence of rate increases ca. 17-15 Ma ("East Papuan Composite Terrane"), ca. 11-6 Ma (Bird's Head region), ca. 2 Ma (north coast ranges) [45]. These authors suggest that the dating and its 
relation to geological processes must be taken with caution, as in any other study including ours. The biological patterns emerging from such analysis are nevertheless significant and beg for explanation.

\section{Biogeography-testing the new terrane interpretation}

We used our geospatial model for New Guinea to make inferences of ancestral states and their evolution in time and space for species occurrence on geological terranes, elevational distribution and according to their recent geographic distribution. "Geology" is essentially addressing historical processes and assuming lineage diversification on land very different in configuration in terms of size and position (and altitude) than present-day New Guinea. "Geography" seeks to make inferences based on the presently observed distribution of species, also invoking geological history (because recent areas if inferred as ancient distribution implies presence of at least some land), but possibly also much more recent processes.

\section{Evolution in the north coast region}

Our hypothesis H1 suggested early evolution on (volcanic) island arcs adrift in the Pacific, prior to collision of these areas of Pacific affinity with the northern Australian plate margin (e.g., the Solomons Arc, work on aquatic bugs, [51] see also work on cicadas [49, 68]). The geography inference reveals two clades showing more pronounced species diversification along the north coast ranges (around nodes $4 / 5$, and 33). This diversification process might have begun as early as $c a$. $9 \mathrm{Ma}$, with more species originating from $c a$. 4 Ma. During that time, we find interactions between north coast ranges and usually nearby parts of the Central Range (west, center or east, Fig. 5). Species across the tree have repeatedly colonized the north coast ranges from different blocks of the Central Range or the Papuan Peninsula next to them. The oldest such split was inferred at node 13 between a species in the Weyland foothills and a group of species in nearby Central Range West. The geology inference recovers a similar picture. At node 33, ca. $5 \mathrm{Ma}$, we infer a switch from occurrence on Australian Plate affinity to Accreted Pacific Plate accreted affinity (and younger overlying sedimentary sequences). Within that clade, the uplifted Australian Plate areas as well as the Transition belt and Post collisional volcanics were more recently colonized. In the clade around node 4 , we infer an earlier presence ( $c a$. $11 \mathrm{Ma}$ ) on areas of Pacific affinity than by simply looking at the Geography coding (ca. $9 \mathrm{Ma}$ ), because geologically, some of the northern parts of the Central highlands are also rocks of Pacific affinity. In summary, we find geographic as well as geological structure that confirms an important role of areas of Pacific affinity for the diversification of Exocelina diving beetles. Under the assumption that present day New Guinea only formed in the past few million years, this might indeed have been in a setting of a proto Papuan archipelago, with smaller islands existing close enough to the northern margin of the Australian plate to allow repeated exchange of biota in both directions. This scenario appears realistic considering that Exocelina diving beetles have frequently been observed by us flying, and are abundantly caught in flight interception traps [61]. Hypothesis $H 1$ is thus partially supported, although the ancestral area is unambiguously uplifted Australian Plate rocks (in terms of geology) of the central range (in terms of geography). This also confirms the results of other biogeographic studies, in particular those assuming a biogeographic origin on the Australian craton and then colonization and diversification on smaller islands to the north [27, 28, 33-35, 43-45, 48].

The Foja Mountains of the Gauttier Terrane have never been studied in a comparative biogeographic framework. We find three colonization events, only in the past $<3 \mathrm{Ma}$ in the clade at node 33, out of other areas of Pacific affinity of the north coast ranges. Note that parts of the Foja Mountains might feature underlying Transition zone material. In any case, Hypothesis H1A, the Foja Mountains as a museum of diversity whereby diversity would have been accumulating for millions of years, does not seem credible in our specific study group.

\section{The role of ultramafic/ophiolite rocks and the Papuan Arc scenario}

Hypothesis $H 2$ suggests that some of the older clades should occur in, or nearby, areas of ophiolite and ultramafic rocks. These are the areas biogeographers sometimes refer to as the ancient, oceanic Papuan Arc (15-11 Ma) [39, 51, 58]. Geographically, the ultramafic/ ophiolite rocks occur in all the major regions we have coded, but we do not infer a strong geographic signal. Rather, we find close affinity with species from rocks of Pacific Plate affinity, Australian Plate affinity, Transition or Post collisional volcanics. This agrees with the actual geological processes that saw continued tectonic activity along the plate boundary, which resulted in further uplift and the tectonic juxtaposition of different terranes against one another along major fault zones, particularly after ca. $6 \mathrm{Ma}$ (Fig. 4). However, we also infer an older collision event (ca. $12 \mathrm{Ma}$ ), at node 16 , with a transition from species on Uplifted Australian Plate rock onto ultramafic/ophiolite. Within that clade, we find geographic interaction between the Central Range West and East in a vicariant species pair (node 17). In terms of geology, some species within that clade are found on Uplifted Australian Plate, Transition or Post collisional volcanics, also predicted by the emplacement process. The geographic distribution of species in clade 16 includes the 
Central Range West + a nearby north coast range (North Weyland). This suggests the comparably early existence of some amount of land, possibly several islands, in that region.

Increased sampling of that particular region would most likely rather suggest Uplifted Australian Plate rocks as MLS at node 16 as we mainly sampled immediately north of the Australian Plate formations, close to the last northern ridge of the Central Range, and then a transect down the northern slopes. The entire actual highland region of Central Range West remains essentially unsampled. The single species from its southern slopes of Central Range West (node 30, E. tsinga), only ca. $60 \mathrm{~km}$ south from our northern localities, is a species vicariant with a southern slope species from further east (E. athesphati) close to the PNG border. In summary, we did not find support for Hypothesis H2. While there might have been diversification events involving ultramafic/ophiolite rocks, their very emplacement process closely relates them with the later collision, uplift and fault movement between the Pacific and Australian plate affinity rocks.

Ultramafic rocks do, however play an important role in generating mountain biodiversity [69], as their soils promote endemic and diverse plant radiations. Streams on ultramafic rocks could be referred to as naturally polluted with heavy metals, so that aquatic fauna might require species physiological adaptations. This was suggested for New Caledonian caddisflies which radiated in streams on ultramafic rocks [70], or for the New Caledonian flora where ultramafic rocks harbor a disproportionately high fraction of endemic vascular plants compared to other areas [71]. In New Guinea, due to the accretion history, the ultramafic rocks make up the northern slopes of the Central Range and the Papuan Peninsula orogen. Aquatic insects are thought to be more diverse there, compared to the southern slopes, which are predominantly composed of limestone [51]. These authors suggest that this could be due to relief and elevation, which is much higher and steeper towards the south, having profound effects on stream diversity, type and shape. Here, intensive surveys of aquatic biota and abiotic factors including water chemistry could help to better untangle factors shaping diversity patterns in the New Guinea orogen.

\section{Evolution in the Central Range, Bird's Head and Papuan Peninsula}

Our hypothesis $H 3$ suggested an early lineage diversification in the present Central Range, possibly in a "proto Papuan archipelago" setting. Specific assumptions were formulated as follows: $(H 3 A)$ the $1300 \mathrm{~km}$ long Central Range initially consisted of several islands, this implies localized radiations in different present-day highland blocks; $(H 3 B)$ there is a temporal sequence from west to the east; $(H 3 C)$ mountains of eastern PNG have existed as a separate island before $25 \mathrm{Ma}$ and harbor old biota.

The geological inference we made clearly shows that the ancestral species of all major clades evolved on uplifted Australian Plate affinity rocks (coded as E), as well as rocks directly associated with the collision of material of Pacific affinity with the Australian plate margin (Transition, ultramafics and Post collisional volcanics, B, C, D). In addition, the geographic inference shows geographic structure in most clades. For Exocelina diving beetles, we have clearly shown that the early evolution likely took place on uplifted Australian Plate and associated rocks in the eastern part of the present-day Papua New Guinea highlands and the Papuan peninsula including the Herzog Mountains, as predicted by some previous authors [23, 28, 33, 42, 51] (see also Table 4). This area ( $\mathrm{E}$ and $\mathrm{C}$ in our coding) corresponds to the "Woodlark Plate including East Papuan Composite Terrane" of [42], but as explained above, their concept of a Woodlark Plate confused modern-day plate delineation and the long-term tectonic evolution of New Guinea.

Hypothesis $\mathrm{H} 3 \mathrm{C}$ assuming eastern PNG as an evolutionary cradle, is here supported and in line with other biogeographic work cited above (and see [33, 48]), but based on our new terrane interpretation, we cannot be certain of the notion that diversification there happened on a large island drifting in the Pacific. However, this does not mean that we cannot envision an archipelagic setting in the region in the wake of the processing forming the present island and before.

In our example, different parts of the Central Range have been colonized by Exocelina in separate clades and at various geological times, e.g., from Central Range East (F) westwards to Central Range Center (E) (e.g., clades 6, 29), or towards Central Range West (D) (clade 16), and towards the Bird's Head $(14,25)$.

We find geographic structure in our diving beetle tree, dating back millions of years, that suggests diversification on separate islands that are now part of the New Guinea central orogen, which gives support to our Hypothesis $H 3 A$. This would confirm the idea of early evolution in a proto Papuan archipelago, and we have clearly identified its gondwanan geological origin. We, however, do not find a clear directionality along the Central Range. We thus can not corroborate Hypothesis $H 3 B$. Interestingly, we do not find colonization out of the Bird's Head region back towards the east. Our results here further highlight the important role and complexity of the New Guinean orogeny, and the orogen as a source of endemic Papuan diversity [33, 41, 48, 72] (Table 4). Unambiguous diversification for the Bird's Head taxa is comparably recent, the crown clades are both estimated at $c a .6 \mathrm{Ma}$, with species mostly associated with uplifted Australian Plate rocks, 


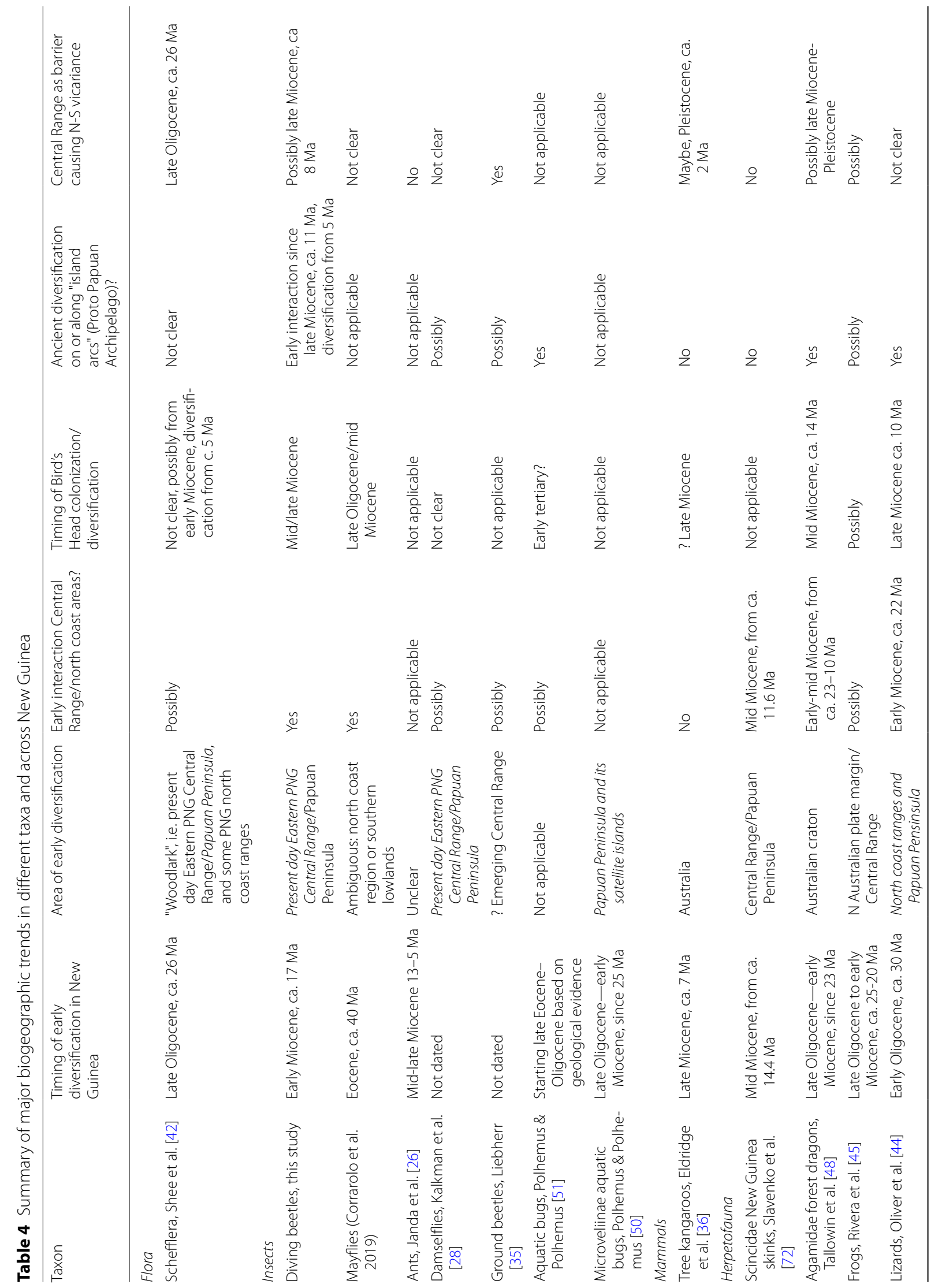




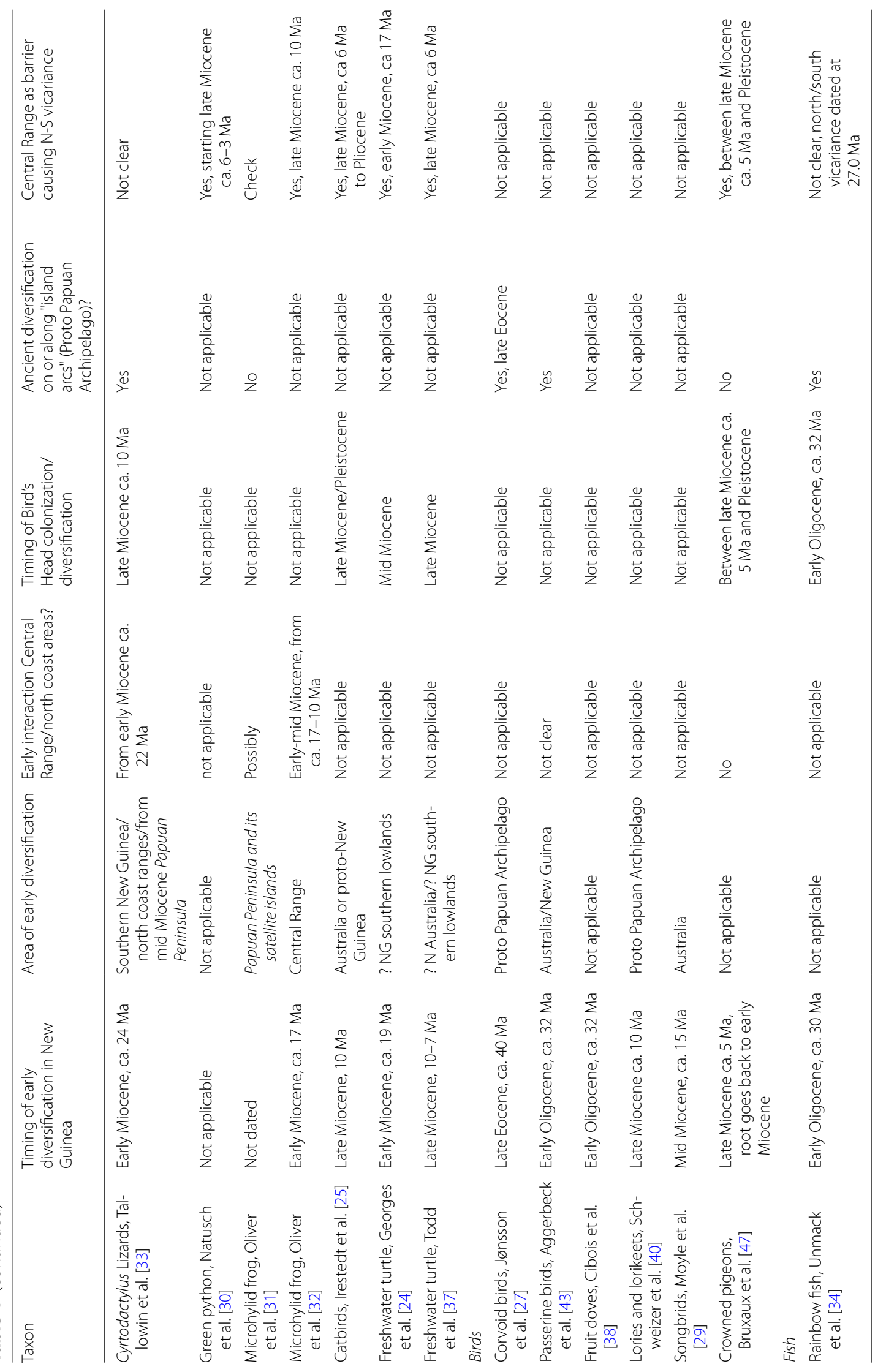


after ca. 4-3 Ma also Pacific, ultramafic, Post collisional volcanics and Transition, suggesting the emplacement, uplift and/or exposure of these geological regions during that time. Presence in the Bird's Head region might however date back up to $c a .13 \mathrm{Ma}$ if stem lineage representatives already occurred in that region (nodes 14, 25). Our estimate would be in line with data e.g., from microhylid frogs [45], but estimates in other studies range from late Oligocene to Pleistocene (Table 4).

However, according to [7], continuous terrestrial habitat in the Bird's Head might only be available since the Pleistocene. Previously, the extent and position of land was highly dynamic, but the continuous existence of smaller islands cannot be ruled out (see also phylogenomic data presented by [21]).

The Central Range remains little explored, and a much denser sampling is needed to understand smaller scale patterns of lineage diversification, in particular to unravel more recent population genetic processes (but see [21]) and the timing and rate of uplift. Towards node 7, we infer one colonization event of the Star Mountains that from ca. $4 \mathrm{Ma}$, gave rise to nine (known) species [73]. Such localized radiations highlight the role of individual larger and strongly structured mountain blocks, either as islands or sky islands [74].

\section{Emergence of general patterns?}

Geological evidence suggests that the present day New Guinea landmass (i.e., land exposed above sea level) came into existence relatively recently (e.g., [7]). However, more and more publications on New Guinea's flora and fauna date back their early diversification to the early Miocene or even late Eocene (Table 4), possibly in an archipelagic setting involving the emerging Central Range. This does not necessarily need to invoke early lineage diversification on oceanic islands arcs (e.g., a volcanic arc), but there is ample evidence for early interactions between the Australian craton and/or Central Range and oceanic areas that nowadays form the north coast ranges. This relates to our hypotheses $\mathrm{H} 1$ and $\mathrm{H} 1 \mathrm{~A}$, ancient diversification along oceanic island arcs, for which our, and other studies (Table 4) deliver some support, but also highlight the role of dispersal between different areas.

The concept of ancient lineage diversification on an island arc of Mesozoic ultramafic rocks (our hypotheses H2) is too simplified; different areas of the Central Range harbouring older fauna might rather represent previously separate insular entities of the emerging Central Range-this concept is captured within our hypothesis $\mathrm{H} 3$ and H3A, which we find supported, in line with other recent publications (Table 4). Our hypothesis $\mathrm{H} 3 \mathrm{~B}$ assumed a temporal colonization sequence from west to the east based on some of the available geological data [75]. However, for the diving beetles, we roughly find the opposite pattern, with colonization occurring from east to west, and more in line with the broader patterns seen in the geological data available across New Guinea and consistent with tectonic models that show sinistral strike slip faulting along the northern margin of New Guinea occurring from east to west $[5,6,18]$ (Fig. 6). Data for other taxa in general are scarce and highlights the need for strongly enhanced biological and geological sampling along the Central Range.

Our hypothesis H3C focused on the Papuan Peninsula. This part of New Guinea (sometimes referred to as East Papuan Composite Terrane EPCT, or Woodlark Plate) has been considered one of the oldest terrestrial areas of New Guinea, possibly existing as a separate island for since $>25 \mathrm{Ma}$ (e.g., [50]). Indeed, several studies (Table 4) point to the Papuan Peninsula as an area of early diversification in New Guinea. We identify colonization events from the Central Range East towards the Papuan Peninsula from the mid Miocene, and then repeated interactions with the Central Range and north coast areas. (Fig. 6). The Bird's Head might have been colonized earlier than expected based solely on geological evidence, but major lineage diversification appears to be more recent, from $c a$. $5 \mathrm{Ma}$ (this study; [42]; Table 4). Here, studies more focused on the Bird's Head, with comprehensive taxon sampling, remain a future task.

\section{Conclusion}

Large scale diversification of New Guinea Exocelina is to a large extent structured geographically, the explanation of which lies in geological time and hints towards early lineage diversification in a proto Papuan archipelagic setting. Towards the tip nodes, processes took place across a more or less existing landscape. We highlighted the need for further studies, with comprehensive taxonomic and geographic sampling. Preliminary data for hyperdiverse weevils suggest that even smaller mountain ranges such as Cyclops can harbour large numbers of endemic species within a single regnus [76], but their biogeographic origins remain to be studied. Also, finer scale investigation using population genomic data as well as research on species' dispersal ecology will help to untangle the processes that led to a high degree of local endemism of such beetles, in our case with closely related species often occurring close to each other such as in clade 7 with a species group endemic to mostly higher elevation of one mountain block (Figs. 4, 5; Additional file 1: Appendix 12). 


\section{Methods}

\section{Review of geological and biogeographic background The north coast region}

To a large extent, the northern part of New Guinea, including parts of the Central Range, are of Pacific affinity. This includes also the Bewani, Adelbert and Finisterre Mountains, parts of the Papuan Peninsula (see also below) as well as New Britain and parts of the Arfak Mountains, Yapen, Biak and Waigeo islands, among others (Fig. 1). Biologists have discussed the biogeographic significance of these elements of Pacific affinity, which has been referred to as the "Solomons Arc" (e.g., [28, 51]); summary in [33]. These authors interpreted this arc to represent an accreted island arc system that shows pronounced species level endemism, possibly derived from times when these terranes were islands adrift in the Pacific. This hypothesis implies an old origin of endemic lineages, as well as an initial stepping-stone dispersal from an Asian or a Pacific source area and then along an island arc with subsequent local speciation. This in turn requires that part of the island arc system was broadly exposed above sea-level for a considerable part of its history, e.g., since the mid-Miocene (15-11 Ma, [33] or earlier (> $30 \mathrm{Ma}$, [43]. We use this assumption as hypothesis $H 1$ as suggested in the introduction.

A very poorly known area of Pacific affinity is the Gauttier Terrane, with the Foja Mountains as its prominent feature. It largely consists of basaltic lavas and breccia (and potentially ultramafic rocks) overlain by carbonates and volcanic ash [3, 77]. Few geological data exist from this region, but it is considered to be related to the Torricelli Terrane to the east, that is a terrane of Pacific affinity thought to be part of an island arc that accreted to New Guinea's north coast after the early Miocene $(<23 \mathrm{Ma})$. Colonization of the Foja Mountains could thus be a comparably old biogeographic event, and this relates to our hypothesis $H 1 A$.

\section{The ultramafics}

Collision of other material of Pacific affinity with the northern edge of New Guinea likely occurred earlier and is represented by the various ultramafic/ophiolite rocks found mainly across central and western New Guinea [6, 51] (Fig. 1). These ophiolite and ultramafic rocks consist of oceanic lithosphere pushed southward and upward on top of the existing New Guinea landmass (i.e., due to obduction). They are considered to have been emplaced onto the northern margin of New Guinea at different times and locations between the late Cretaceous and the early Miocene (i.e., $100 \mathrm{Ma}$ to $c a$. $20 \mathrm{Ma}$ ) [3, 14]. These seafloor rocks were subsequently 'sandwiched' between the fold and thrust belt of New Guinea's Central Range, as well as the northern accreted terranes of Pacific affinity ("Solomons Arc" discussed above) during the late Miocene (11-5 Ma) to present day. The ophiolite sequences include the Irian Ophiolites (in Papua Province, Indonesia), the April Ultramafics (western Papua New Guinea, PNG), and the (east) Papuan Ophiolite (Papuan Peninsula, PNG) [2, 3] and these broadly correspond to the "Papuan Arc" terrane of [51]. We note that there are other areas of similar geology in the Cyclops Mountains [78] and the Mount Gamey area north of the Weyland Mountains [79], however, limited geological data in these regions means that little is known about their provenance and tectonic history.

Pioneering biogeographic work by $[51,58]$ suggested that the "Papuan Arc" was adrift in the Pacific and gave rise to genus level endemism. The ophiolites were suggested to have also played a role as stepping-stones for Asian fauna on their way to present day New Guinea. This hypothesis is not strongly supported by geological evidence, as: (1) ophiolites by definition are sections of the seafloor and the upper mantle that have been thrust on to continental crust - this means that ophiolites found on landmasses today, were covered by $>1000 \mathrm{~m}$ of seawater prior to their obduction, and could not harbor terrestrial life, and (2) the New Guinea ophiolites certainly stem from Pacific areas remote from an Asian source area. Note that the younger volcanic arc rocks of Pacific affinity would have likely been submerged volcanoes or small volcanic islands prior to their collision with New Guinea (see [41]). However, for our present phylogenetic analysis of one genus-level radiation, we suggested hypothesis $H 2$, i.e. that some of the older clades should occur in, or nearby, areas of ophiolite and ultramafic rocks (e.g., Mesozoic ultramafic rocks, Fig. 2).

\section{Central Range, Bird's Head and Papuan Peninsula}

The spine of New Guinea is the $1300 \mathrm{~km}$ long and up to $150 \mathrm{~km}$ wide central highland chain, otherwise known as the Central Range, consisting of the major geographic features, Maoke, Bismarck and Owen Stanley Range. It stretches from the easternmost end of the Bird's Head area $\left(c a .135^{\circ} \mathrm{E}\right)$ to $c a .145^{\circ} \mathrm{E}$, which is the westernmost end of the Owen Stanley range on the Papuan Peninsula. The latter is the Bird's tail and eastward extension of the Central Range. More than 20 summits lie above $4000 \mathrm{~m}$ altitude, and summits above $3000 \mathrm{~m}$ are common. It includes a major fold-and-thrust belt in the Central Range which represents the deformed passive margin of the Australian continent. Prominent features include the Snow and Star Mountains as well as the Papuan Peninsula. Available geological data indicates that uplift propagated westward along the northern section of Papua New Guinea (i.e., within the 'Solomons Arc' 
region) at 8-5 $\mathrm{Ma}$-this was associated with the strikeslip motion at the plate boundary at this time [18]. The Central Range was uplifted within the last $5 \mathrm{Ma}$, with uplift propagating from the north towards the south $[4$, 18]. There is some evidence that indicates this uplift may have propagated westward from Papua New Guinea, into Papua at $\sim 2-3$ Ma [5, 13], as well as eastward (e.g., [75]), including rapid rates of uplift after $3 \mathrm{Ma}$ in the Papuan Peninsula (e.g., the Dayman Dome: [80] [81]).

There is no doubt that New Guinea also records evidence of earlier tectonic events that would have driven uplift in different parts of the island (e.g., a model proposed by [82] suggested that an underthrusting of the Australian continent beneath an Inner Melanesian arc resulted in an orogeny restricted to eastern New Guinea (forming the Papuan Peninsula Orogen, Fig. 1, ca. 30-35 Ma). This conceptual model is supported by low temperature thermochronology data that shows rocks of the Müller Range underwent a phase of early Eocene to Oligocene cooling and interpreted to provide potential evidence of the initiation of plate collision and associated uplift [83]. This event, together with a drop in global sea level during the late Oligocene-early Miocene (e.g., [84, 85]) resulted in large areas of New Guinea being exposed above sea-level (e.g., [7, 75, 86]). However, much of New Guinea was submerged again during the mid-late Miocene (ca. 5-15 Ma) due to subsidence outpacing a continued decline of global sea level. The time and extent to which land began to emerge during and after this time ultimately depends on the interpretation of the available geological data.

One piece of evidence that has been used to explain the emergence of land during the Miocene are the rocks classified as the Makats Formation, found in the Mamberamo region north of the Central Range. These sedimentary rocks were most likely deposited in relatively deep water, but contain detritus, including metamorphic rocks that must have been sourced from exposed land [86]. There is no firm evidence to indicate whether the source of the material was from the north (e.g., island arcs) or the south (e.g., uplifted 'Australian' crust) [86]. Despite this, [75] proposed that the metamorphic detritus within the Makats Formation were most likely sourced from a $>500 \mathrm{~km}$ distant landmass that first emerged in the westernmost part of the Central Range. The timing of this emergence was originally reported by [75] $c a$. 16-14 Ma corresponding to the maximum depositional age of the Makats Formation. We revised this reported age using the planktonic foraminifera that occur within the Makats Formation (i.e., first reported by [86] together with the currently accepted age ranges for the diagnostic planktonic foraminifera within the Makats Formation using the Mikrotax database (http://www.mikrotax.org/pfora ms-last accessed 7 April 2020) [87]. Based on this, the Makats Formation was most likely deposited between $c a$. 13.4 Ma and $c a$. 10.5 Ma (and most certainly no younger than $c a .6 .8 \mathrm{Ma}$, based on the oldest ages reported for the overlying Mamberamo Formation). Smaller islands may also have been present from $c a$. $15 \mathrm{Ma}$. This is consistent with low-temperature thermochronology data and thermal history modelling (e.g., $[4,18,83]$. The Central Range region was considered to have grown laterally and in height, gaining maximum elevations of up to $2000 \mathrm{~m}$ by $8 \mathrm{Ma}$, and $4000 \mathrm{~m}$ by $6 \mathrm{Ma}$ [75]. Towards the east (Papua New Guinea, PNG), the Central Range orogeny appears to be younger [82]. The Central Range continued to grow as the fold-and-thrust belt rapidly developed from $5 \mathrm{Ma}$ to present. This period of time also saw the formation of mountains associated with crustal stretching and metamorphic core complex development (e.g., the Wandamen Peninsula in West Papua [13] and the Dayman Dome of the Papuan Peninsula, e.g., [80, 81]). New Guinea's emergence from the sea was progressive as there were multiple phases of uplift and submergence in western New Guinea over the past $5 \mathrm{Ma}$ [7]. So, while sections of the Central Range were being uplifted from $8 \mathrm{Ma}$, other regions such as the Papuan Peninsula, were not uplifted until the Early Pliocene, and the final stage of uplift across the island likely occurred between $1 \mathrm{Ma}$ and present day [7].

Some studies suggest an older age for the emergence of the area spanning the Central Range of eastern PNG and the Papuan Peninsula including Herzog Mountains, e.g., referring to that region as "Woodlark Plate" [42], or, more focussed on the Papuan Peninsula including Herzog Mountains, as "East Papuan Composite Terrane, EPCT" $[28,33,50]$. The area interpreted as the EPCT is a concept that was proposed by [77]. It is said to consist of a series of crustal fragments that were torn off the northern margin of New Guinea in the Cretaceous or earlier. These rocks supposedly accreted with other crustal fragments from the Pacific between 52 and $23 \mathrm{Ma}$, all of which later collided with the northern margin of New Guinea during the Miocene [77]. The EPCT formation could also be linked to what [82] describe as the Oligocene Peninsular orogeny ( $c a$. 35-30 Ma). The remnants of the EPCT today span the modern-day Papuan Peninsula including the Herzog Mountains. Based on this conceptual tectonic model, some biogeographers have assumed that the EPCT may have formed islands or a landmass north of New Guinea before $25 \mathrm{Ma}$, or at least representing one of the oldest terrestrial habitats in the proto Papuan archipelago (e.g., [23, 33, 42, 45, 48, 51]). In such conceptual models, the EPCT (and "Woodlark Plate" in [42] are proposed to harbor old biota and serve as source area for other parts of New Guinea. 
However, the geological data on which the concept of the EPCT was formed simply indicates that a body of water developed between rocks of Australian Plate affinity along the northern margin of New Guinea [77]. It is unclear: (1) how wide this gap was; (2) whether all land connections were severed, and (3) whether this body of water was an ocean, or a rift valley that was subsequently inundated during higher sea levels. Available geological data does not indicate whether the EPCT was or was not exposed above sea-level before its final accretion to the northern margin of New Guinea during the Miocene. Considering these points, there is a high level of uncertainty as to whether the EPCT existed, and if it did, to what extent it may have been an emergent landmass within the Pacific Ocean prior to the middle to late Miocene. Rather than interpreting our data using a highly uncertain, conceptual tectonic model, we instead focus on whether there is any difference in which species are found within the different terrane affinities in the Papuan Peninsula, as well as the evidence that indicates the Papuan Peninsula was uplifted from the Miocene or later. To allow comparisons between biogeographic studies, in this paper, the rocks that others recognize as belonging to the EPCT correspond with the region marked by the East Papuan Ophiolite (Fig. 1). Similarly, the concept of the "Woodlark Plate" and its long-term biogeographic significance as discussed in [42] is highly problematic. This work used a map of the modern-day plate boundaries [88], where plate boundaries have largely been drawn on the basis of earthquake locations and GPS velocity data that suggest parts of the Earth's crust are moving as a cohesive plate. Therefore, this does not outline entities for historical analyses that span millions of years.

Our hypothesis $H 3$ relates to that, suggesting an early diversification on the present Central Range, possibly in an initial setting of a chain of islands, and subsequent colonization of surrounding areas such as the Bird's Head and the Papuan Peninsula. This scenario was in part tested by [41], who suggested recent colonization of the Bird's Head and Papuan Peninsula's out of the Central Range, and [45] who found a colonization sequence from craton and later Papuan Peninsula (EPTC), to the Bird's Head region and then areas with Pacific affinity.

We test this further under the following assumptions: (hypothesis H3A) the $1300 \mathrm{~km}$ long Central Range initially consisted of several islands, this implies localized radiations in different present-day highland blocks; (hypothesis $H 3 B$ ) there is a temporal sequence from west to the east; (hypothesis H3C) mountains of eastern PNG have existed as a separate island before $25 \mathrm{Ma}$ and do therefore harbor fauna older than expected based on the above geological scenarios, and served as source area for other parts of New Guinea.

\section{Assembly of the geological map}

The geological terrane map that is shown in Fig. 2, and online at https://arcg.is/189zmz, is a simplification of numerous 1:250,000 scale geological maps of Indonesian New Guinea (currently Papua and West Papua Provinces, previously known as "Irian Jaya") and Papua New Guinea. The Indonesian maps were developed by the Indonesian Geological Research and Development Centre (GRDC) (Pusat Penelitian dan Pengembangan Geologi (Indonesia)) and the Australian Bureau of Mineral Resources (BMR), now known as Geoscience Australia. The Papua New Guinea maps were developed by the Papua New Guinea Mineral Authority as well as the Australian Geological Survey Organisation (AGSO), now known as Geoscience Australia (for map sources and methods, see Additional file 1: Appendix 1).

Digital scans of the Indonesian New Guinea geological maps were orthorectified in ArcGIS v10.4 using the WGS84 datum. Each geological unit was mapped as a separate polygon and was assigned metadata according to the map rubric. Each polygon was classified according to one of seven geological terranes (Table 1). For Papua New Guinea, GIS maps were purchased from the PNG Mineral Authority (PNG_Geol250, 2002) and these were classified according to the same seven geological terranes as were used for Indonesian New Guinea. Some minor editing of the polygons was made to cut the digitized polygons to fit the current coastline. While every effort was made to quality check the data, readers should note that the digitization and reclassification involved individually modifying the attributes of $>20,000$ polygons. Those polygons with a common terrane attribute and shared boundary were later merged to reduce the size of the datafile. Considering the size and complexity of the geological map, we expect that there will be minor errors. Readers should also note that the geological boundaries that we present have been digitized from hardcopy paper maps. There is some component of uncertainty associated with the original hardcopy maps. For instance, the regions of adjoining map sheets show considerable differences in the extent or continuity of particular rock types, particularly at the international border between Indonesia and PNG. Also, most of the maps were drawn before GPS was widely available, meaning there is an issue with the true location of the base maps that were used as well as the geologist's ability to locate themselves on the map. Those who produced the PNG_Geol250 (2002) data estimated the geological boundaries in the digital dataset have an accuracy between $250 \mathrm{~m}(1 \mathrm{~mm}$ at 1:250,000) and $3.75 \mathrm{~km}$ (about $1.5 \mathrm{~cm}$ at 1:250,000 map scale), with the uncertainty being greatest in the highland regions and at the edge of adjoining map sheets. The Irian Jaya series maps likely have a similar level of spatial uncertainty. This 
does not account for uncertainty associated with distortion of the original paper maps before or during scanning. Having said this, readers should also note that the map presented in Fig. 2 is a much more detailed general terrane map of New Guinea compared to what is presented in earlier geological review papers (e.g., $[2,3]$ ), and more importantly, the map is a much more accurate representation of the geology of New Guinea compared to the maps used in most existing biogeography papers.

\section{Geospatial analysis}

The latitude, longitude and altitudinal data obtained from a handheld GPS unit at each sample site were compiled in a database leading to 638 observations at 303 mapped localities. For instances where a reliable altitude could not be obtained in the field (e.g., due to dense tree cover), we assigned a value based on the sample site position and the corresponding cell from a digital elevation model (constructed from the ETOPO1 Bedrock Global Relief Model: [89]. Each database entry was classified with a number between one to five to represent the altitudinal range of each sampling site $(<500 \mathrm{~m} ; 500-1000 \mathrm{~m}, 1000$ $1500 \mathrm{~m}, 1500-2000 \mathrm{~m}$ and $>2000 \mathrm{~m}$ ), as well as a number between one and five to represent the geological terrane that each sampling site was encapsulated by (using the values recorded in Additional file 2: Appendix 2). The numerical value for the altitude and terrane was required to perform the Grouping Analysis tool (discussed below). Each database entry was double-checked as there were several instances where a sample site lay near a boundary of two terranes. In such instances, a decision was made to retain this classification, or to assign it to another terrane. This decision was most commonly employed when sample sites were located near the boundary between 'Australian Plate affinity' and 'Pacific Plate affinity' and were instead reassigned to the 'Transition' classification.

A one-to-many database join was used to assign the latitude, longitude, altitude and geological terrane to each identified species. Each database entry was also assigned a unique value within the database (Additional file 1: Appendix 2).

The Grouping Analysis tool, part of the ArcGIS Spatial Analysis toolbox extension was used to explore potential spatial relationships within the database. This technique utilizes unsupervised machine learning methods to determine natural groupings within a dataset. This technique is considered unsupervised because it does not require a set of pre-classified features to guide or train the algorithm that determines groupings within a spatial database. While our ultimate aim of employing this technique was to determine if there are spatial patterns within our database, we did not apply a spatial constraint to the algorithm, which means that the algorithm assumes there is no spatial correlation between any two sample locations. This means that if a spatial pattern is identified within the analysis, it is dependent on the altitude or underlying geology (or both). The tool requires the user to specify how many populations between 2 and 15 might exist within the dataset. After running the algorithm using different input parameters, we limited the final output to five populations. Readers should also note that it is possible that the numerical value assigned to represent the altitudinal range and geological terrane might also influence the results determined by this algorithm. Considering these limitations, we used the tool for data exploration purposes only, using it to test if any apparent relationship could be identified between species and altitude, species and underlying geology and species plus both altitude and geology.

\section{Taxon sampling and molecular biology}

We build upon the recent molecular framework of [41, 46], and added data from 41 additional species of Exocelina diving beetles compared to the most recent molecular treatment of the genus [46]. Most of the data sequenced for these new taxa was derived from older museum specimens. Complete genomic DNA was extracted with a Qiagen DNeasy Blood \& Tissue kit (Hilden, Germany) using head and pronotum, or entire beetles. Using PCR protocols described in [41], we amplified and sequenced fragments of the following genes; mitochondrial cytochrome c oxidase I ( $\operatorname{cox} 1)$, cytochrome c oxidase II (cox2) and cytochrome b (cob), in addition to the nuclear histone $3(\mathrm{H} 3)$, histone $4(\mathrm{H} 4)$, $18 \mathrm{~S}$ rRNA (18S), Carbomoylphosphate synthase (CAD) and Alpha-Spectrin (Asp). All new sequences will deposited in GenBank after publication of their formal names in $[90,91]$ so that new data can be uploaded with their final names. The matrix for this project has been deposited in Dryad: https://doi.org/10.5061/dryad.ns1rn8prj.

\section{Alignment and phylogenetic inference}

The resulting sequences were edited in Geneious R11 (Biomatters, USA) and checked for sequencing errors. Once assembled, the consensus sequences were aligned using MUSCLE [92] with existing datasets [41, 46] as well as a selection of outgroups chosen from the comprehensive phylogeny of [93] to facilitate the use of secondary calibrations in the BEAST divergence time analyses (see below). The resulting gene fragment alignments were checked for stop codons or indels and concatenated to produce a final matrix comprising 237 specimens (including 205 Exocelina specimens), and 4226 aligned nucleotides.

The concatenated matrix was analyzed in a maximum likelihood framework using IQ-TREE 1.6.6 [94]. The 
matrix was a priori subdivided into non-coding gene fragments and codon positions of coding gene fragments for a total of 22 partitions. The optimal partitioning scheme and corresponding models of nucleotide substitutions were searched simultaneously using ModelFinder [95] as implemented in IQTREE 1.6.6 among all available models and selected using the corrected Akaike Information Criterion (AICc) (see Additional file 1: Appendix 3 for the resulting partitioning scheme and models used in the IQ-TREE analyses). We performed 500 tree searches to avoid local optima. For each tree search, we performed branch support calculations with 1000 ultrafast bootstrap replicates (UFBoot, [96, 97] and $1000 \mathrm{SH}$-aLRT tests [98]. We used the hill-climbing nearest-neighbor interchange topology search strategy implemented in IQ-TREE to avoid severe model violations leading to biased ultrafast bootstrap estimations [97].

\section{Divergence time estimation}

There is no fossil known of the genus Exocelina, and the fossil record within Copelatinae is very scarce. Previous attempts at estimating absolute divergence times across Copelatinae have suggested different hypotheses pertaining to the temporal evolution of these beetles [41, 46, 65]. These discrepancies are largely linked to alternative calibration strategies. Recently, a new fossil-based dated phylogenetic framework for diving beetles has been developed based on the phylogeny of [66]. We rely on multiple secondary calibrations from this study to calibrate clocks and estimate divergence times. Specifically, we constrained the split between Dytiscinae and closely related subfamilies Copelatinae, Cybistrinae and Laccophilinae (i.e., the stem of Dytiscinae in [66] and the root of the tree in the current study) with a uniform distribution encompassing the $95 \%$ credibility interval recovered for this node in [66] (i.e., 122-141.4 Ma). We enforced the sister relationships between Laccophilinae and Cybistrinae in the BEAST analyses following [66]. We also constrained the crown of Cybistrinae (95\% HPD $=37.4-$ 81.5), crown of Laccophilinae (95\% $\mathrm{HPD}=44.7-98.3$ ), crown of Copelatinae $(95 \% \mathrm{HPD}=58-114.2)$, crown Cybistrinae + Laccophilinae $\quad(95 \% \quad \mathrm{HPD}=71.6-120.6)$ and crown of Copelatinae + Cybistrinae + Laccophilinae $(95 \% \mathrm{HPD}=88.8-135.5)$ with uniform prior distributions matching the 95\% credibility intervals recovered in [66].

We used PartitionFinder 2 with the greedy algorithm, linked branch lengths and the set of models included in the program BEAST 1.10.4 [99], to select the optimal partitioning scheme and models of nucleotide substitution using the same 22 initial partitions as in the IQ-TREE analyses. The partitions and corresponding models of nucleotide substitution were selected with the Bayesian Information Criterion. We either assigned one clock to the mitochondrial partitions and another to the nuclear partitions (2 clocks in total), or a different clock to each partition recovered in PartitionFinder (12 clocks in total, see Additional file 1: Appendix 4 for the best partitioning scheme and models used in the BEAST analyses). We used relaxed molecular clocks with uncorrelated rates drawn from a lognormal distribution in BEAUti 1.10.4 [99]. The Tree Model was selected as Yule or birth death in different analyses. All other parameters were left to default. The analyses were conducted in BEAST 1.10.4 with 100 million generations, a parameter and tree sampling every 5,000 generations, and estimation of marginal likelihood using path-sampling and stepping-stone sampling with default parameters (chainLength $=1,000,000$; pathSteps $=100 ; \alpha=0.3$ ). The best scoring IQ-TREE topology out of 500 independent ML tree searches was constrained as a fixed input tree (with the unique modification being the enforced sister relationship between Laccophilinae and Cybistrinae) by manually editing the BEAUti.xml file. The four different analyses were compared based on their marginal likelihood estimates (MLE), and the one with the lowest MLE was used for further analyses.

\section{Ancestral state reconstructions}

We used the Bayesian Binary MCMC (BBM) method as implemented in RASP 4.2 [100] to estimate ancestral ranges across the New Guinean Exocelina radiation. To perform the reconstructions, we used the best BEAST maximum credibility clade tree based on MLE comparisons (Table 2). We coded each taxon with geology and geography (Additional file 1: Appendix 2). For altitude and geology, beetles were assigned to different categories using the geospatial model we compiled for this project. The altitude was coded using five discrete categories: (1) 0-500 m, (2) 501-1000 m, (3) 1001-1500 m, (4) 1501$2000 \mathrm{~m}$, (5) above $2000 \mathrm{~m}$. These intervals are subjective but provide the framework to visualize the three-dimensional distribution of the beetles. While we provide an outline of the elevational evolution of New Guinea in the introduction, note that it is currently not possible to suggest a reliable paleoaltimetric model for the island. Uplift was comparably fast with a rate of up to $10 \mathrm{~mm} / \mathrm{year}^{-1}$ for some areas (e.g., the Wandamen Peninsula: [13] and up to $51 \mathrm{~mm} /$ year $^{-1}$ for others (e.g., $17-51 \mathrm{~mm} /$ year $^{-1}$ D'Entrecasteaux Island; [101]), at least from $3 \mathrm{Ma}$ to the present. This might also apply for (parts of the) Central Range, which has seen rapid uplift in the past $5 \mathrm{Ma}$. But the rate of uplift might vary over time and region, and the supposed submergence of vast areas would add additional uncertainty. The geology was coded based on our geological terrane map of New Guinea. For the coding, the three principal terranes were in part subdivided 
as follows: Northern belt into: "accreted Pacific Plate affinity" and "ultramafic"; the transition belt into:"Post Collisional Volcanics" and "Transition", and gondwanan material as "Uplifted Australian Plate affinity" (see introduction).

The geographic coding does not consider the geological history but looks at the existing island and its major regions (https://arcg.is/189zmz "New Guinea Regional Classification"). We here differentiate between six areas: the north coast mountain ranges including Wandamen (coded as A), the Bird's Head including its satellite islands (B), the Bird's Neck (Lengguru) (G), the Papuan Peninsula including the Herzog Mountains to its north east (C), as well as three blocks of the Central Range (from the Weyland/Paniai region in the west up to Baliem Valley at $c a .139^{\circ} \mathrm{E}$ (coded as D), from Baliem valley east to the Star Mountains including in Sandaun Province of PNG $142^{\circ} \mathrm{E}$ (coded as E), and finally the mountain block east of Sandaun to $145^{\circ}$ E) (coded as F). This geographic delineation is simplified and meant to possibly reveal large scale biogeographic patterns and is not based on previously suggested New Guinea areas of endemism (e.g., [102]. It is also important to note that the delineation of the geographic areas is subjective to some degree; for example, in the west of area C, mainly Papuan Peninsula, we include the Herzog Mountains (that could alternatively be assigned to "A", north coast ranges). The single species from the Bird's Neck (Lengguru: Kaimana) region was coded in its own region $(\mathrm{G})$. Alternatives would be assigning the Bird's Neck to the Bird's Head region (B) or the Central Range West (D) (Additional file 1: Appendix 11). Parts of the central range northern slopes, that are geologically also of Pacific affinity (Figs. 2, 4) were coded as geographically belonging to the Central Range.

All analyses were conducted in a Bayesian framework in RASP 4.2. using a Markov chain Monte Carlo method with 10 chains running for 1 million generation and with a sampling every 1,000 generations. We used the estimated F81 model for all runs. The rest of options were left to default in BBM.

\section{Diversification rate dynamics estimation}

We estimated diversification rate dynamics within Exocelina using the program BAMM 2.5.0 [103]. The analyses were performed with four reversible jump MCMC running for 1 million generations and sampled every 1000 generations. Parameter priors were estimated in $\mathrm{R}$ using the setBAMMpriors function (expectedNumberOfShifts $=1.0 ; \quad$ lambdaInitPrior $=0.800$; lambdaShiftPrior $=0.067$; muInitPrior $=0.800$ ). We used different priors $(0.1,1,2$ and 5$)$ for the parameter controlling the compound Poisson process that determines the prior probability of a rate shift along branches of the chronogram. Our taxon sampling comprises 142 species of the New Guinean radiation (described and undescribed ones), yet we hypothesize that the extant species richness of the New Guinean radiation is closer to $c a .190$ species. Therefore, the global sampling fraction was setup to 0.75 (New Guinean radiation only) in the different analyses. This is arguably more realistic than relying on the current described diversity (relying on the latter did not affect the results, data not shown). The BAMMoutput files were analyzed using BAMMtools 2.1.6 [104]. The posterior distribution of the BAMM analysis was used to estimate the best shift configuration and the $95 \%$ credible set of distinct diversification models.

We also tested the fit of various diversification dynamics scenarios to the entire New Guinean Exocelina diving beetle radiation. We relied upon constant-rate, timedependent and diversity-dependent models of diversification as implemented in a maximum-likelihood framework. The different models were fitted using the fit_bd function rom the R package RPANDA 1.8 [105] and the $d d \_M L$ function from the R-package DDD 4.3 [106], (see i.e., [107] for more details). Missing taxon sampling at the species level was also taken into account, using a global fraction of the expected species richness in the genus (i.e., $142 / 190=c a$. 0.75).

We tested the fit of the following models: (1) speciation rate constant through time with no extinction (BCST), (2) speciation and extinction rates constant through time (BCSTDCST), (3) speciation rate varying exponentially through time with no extinction (BtimeVarEXPO), (4) speciation rate varying linearly through time with no extinction (BtimeVarLIN), (5) speciation rate varying exponentially through time with constant extinction (BtimeVarDCSTEXPO), (6) speciation rate varying linearly through time with constant extinction (BtimeVarDCSTLIN), (7) extinction rate varying exponentially through time with constant speciation (BCSTDtimeVarEXPO), (8) extinction rate varying linearly through time with constant speciation (BCSTDtimeVarLIN), (9) speciation and extinction rates varying exponentially through time (BtimeVarDtimeVarEXPO), (10) speciation and extinction rates varying linearly through time (BtimeVarDtimeVarLIN), (11) speciation rate varying linearly with diversity without extinction (DDL), (12) speciation rate varying linearly with diversity with constant extinction $(\mathrm{DDL}+\mathrm{E}),(13)$ speciation rate varying exponentially with diversity with constant extinction $(\mathrm{DDX}+\mathrm{E})$, (14) speciation and extinction rates varying linearly with diversity (DDL + EL).

In the time-dependent and diversity-dependent models, speciation and extinction rates (respectively $\lambda$ and $\mu$ ) could vary as a continuous function of time or diversity. This function was assumed to be either linear or 
exponential. The parameters $\alpha$ and $\beta$ measure the sign and rapidity of time-variation for respectively speciation and extinction rates. Positive values of $\alpha$ or $\beta$ can be interpreted as an indicator of speciation or extinction slowdown, while negative values indicate an acceleration of speciation or extinction. The parameter $\mathrm{K}$ measures the carrying-capacity in diversity-dependent models. These 14 models were compared with the AICc and $\triangle \mathrm{AIC}$ to determine best-fit to the time-calibrated phylogeny.

\section{Abbreviations}

HPD: Highest posterior density; Ma: Million years ago; rRNA: Ribosomal RNA.

\section{Supplementary Information}

The online version contains supplementary material available at https://doi. org/10.1186/s12862-021-01764-2.

Additional file 1: Appendix 1. Methodology for the construction of the New Guinea geological terrane map including references for map building. Appendix 2. Separate Excel file containing the geospatial data. Appendix 3. Partitioning scheme and models of nucleotide substitution for IQ-TREE ML tree searches as selected under ModelFinder. Appendix 4. Partitioning scheme and models of nucleotide substitution for BEAST divergence time estimation as selected using PartitionFinder. Appendix 5. Best scoring IQ-TREE ML tree (SH-aLRT/UFboot at nodes). Appendix 6. Best scoring IQ-TREE ML tree in newick format. Appendix 7. Best BEAST analysis chronogram with median ages. Appendix 8. Best BEAST analysis chronogram with median ages in newick format. Appendix 9. Spatial analysis map. Appendix 10. Heat maps for geology, altitude and geospatial analysis groups and projected onto the phylogenetic hypothesis. Appendix 11. Detailed outputs of BMM analyses. Appendix 12. Altitudinal distribution map. Appendix 13. Results of BAMM with a prior of 0.1.

Additional file 2. Separate Excel file containing Appendix 2, summary of the geospatial data.

\section{Acknowledgements}

This study is dedicated to our late friend and colleague Ignacio Ribera who greatly contributed to our understanding of water beetle diversity and evolution over the years, and who even more importantly was a dear friend and teacher. Thanks are especially due to Vojtech Novotny, Aloysius Posman, Bangan John, Andrew Kinibel, and Sentiko Ibalim, whose help in the field is greatly appreciated. We thank three anonymous reviewers for their very helpful evaluation of our work, as well as Paul Oliver and Oliver Tallowin for commenting on parts of our manuscript.

\section{Authors' contributions}

LW, MB, EFAT designed this study. MB wrote the first draft manuscript. TVR, $\mathrm{BS}, \mathrm{RP}, \mathrm{KS}, \mathrm{SS}, \mathrm{HS}, \mathrm{MB}$ organized and conducted fieldwork. MB, AL generated sequence data. HS led the taxonomic investigation. LW analysed geological data and built the arcgis website. EFAT conducted phylogenetic analysis. $M B, E F A T, T V R, L W$ built the figures. All authors read and approved the final manuscript.

\section{Funding}

Support for the study was provided by the FWF (Fonds zur Förderung der wissenschaftlichen Forschung - the Austrian Science Fund) through the projects P 24312-B17 and P 31347-B25 to Helena Shaverdo. Michael Balke was supported by the German Science Foundation (DFG BA2152/3-1, 6-1, 7-1, $11-1,11-2,17-1,19-1,19-2)$. We are grateful for the generous support from the SNSB-Innovative scheme, funded by the Bayerisches Staatsministerium für Wissenschaft und Kunst. Cooperation with Indonesian counterparts was greatly supported by IndoBioSys, a project funded by the German Federal Ministry of Education and Research (BMBF) within the bilateral "Biodiversity and Health" funding programme (Project numbers: 16GW0111K, 16GW0112). Fieldwork was supported by the UK Darwin Initiative project "Training the next generation of PNG conservation biologists" to Aland Stewart, the Wildlife Conservation Society, PNG Program (now PNG Institute for Biological Research), Goroka, EHP, Papua New Guinea, as well as the PNG Binatang Research Center, Madang, Papua New Guinea. The funding bodies played no role in any aspect of the study itself, including its design, the sampling procedures employed, the analyses and interpretation of the data and the writing of the manuscript. Open access funding provided by the Natural History Museum of Geneva.

\section{Availability of data and materials}

References to the data generated or analyzed during this study are included in this published article. The sequence data are deposited in Dryad: https:// doi.org/10.5061/dryad.ns1 rn8prj. The geospatial data are online under: https:// arcg.is/189zmz. CETAF user statement: „Data on genetic material contained in this taxonomic publication are published for non-commercial use only. Utilization by third parties for purposes other than non-commercial scientific research may infringe the conditions under which the genetic resources were originally accessed, and should not be undertaken without obtaining consent from the original provider of the genetic material."

\section{Ethics approval and consent to participate}

Fieldwork and/or research permits were issued by the responsible national and/or provincial authorities. For every field locality traditionally owned by a Melanesian society, village elders, landowners and/or local authorities were informed and involved in the research as field guides where possible.

\section{Consent for publication}

Not applicable.

\section{Competing interests}

The authors declare that they have no competing interests.

\section{Author details}

${ }^{1}$ Natural History Museum of Geneva, CP 6434, 1211 Geneva 6, Switzerland. ${ }^{2}$ GeoQuEST Research Centre, School of Earth, Atmospheric and Life Sciences, University of Wollongong, Wollongong, NSW 2522, Australia. ${ }^{3}$ Naturhistorisches Museum Wien, Burgring 7, 1010 Vienna, Austria. ${ }^{4}$ SNSB-Zoologische Staatssammlung München, Munich, Germany. ${ }^{5}$ Department of Environmental Science, Policy and Management, University of California, Berkeley, CA, USA. ${ }^{6}$ Institute for Biodiversity Science and Sustainability, California Academy of Sciences, San Francisco, CA, USA. ${ }^{7}$ Department of Biology, Universitas Cenderawasih (UNCEN), Waena, Papua, Indonesia. ${ }^{8}$ Department of Biology, Faculty of Sciences and Mathematics, State University of Papua (UNIPA), Jalan Gunung Salju Amban, Manokwari 98314, West Papua, Indonesia. ${ }^{9}$ Walian 2, Tomohon Selatan 95439, N Sulawesi, Indonesia. ${ }^{10}$ Museum Für Naturkunde - Leibniz Institute for Evolution and Biodiversity Science, Invalidenstraße 43, 10115 Berlin, Germany. ${ }^{11}$ University of Papua New Guinea, Port Moresby, Papua New Guinea. ${ }^{12}$ Department of Entomology, SNSB-Zoologische Staatssammlung München, Münchhausenstrasse 21, 81247 Munich, Germany.

Received: 18 September 2020 Accepted: 9 February 2021

Published online: 06 April 2021

\section{References}

1. Gressitt JL. Biogeography and ecology of New Guinea, vol. 1. London: DrW. Junk; 1982.

2. Baldwin SL, Fitzgerald PG, Webb LE. Tectonics of the New Guinea region. Annu Rev Earth Planet Sci. 2012;40(1):495-520,

3. Davies HL. The geology of New Guinea - the cordilleran margin of the Australian continent. Episodes. 2012;35(1):87-101.

4. Hill K, Gleadow A. Uplift and thermal history of the Papuan Fold Belt, Papua New Guinea: apatite fission track analysis. Aust J Earth Sci. 1989;36(4):515-39.

5. Weiland RJ, Cloos M. Pliocene-Pleistocene asymmetric unroofing of the Irian fold belt, Irian Jaya, Indonesia: apatite fission-track thermochronology. Geol Soc Am Bull. 1996;108(11):1438-49.

6. Hill KC, Hall R. Mesozoic-Cenozoic evolution of Australia's New Guinea margin in a west Pacific contex. In: Hillis RR, Müller RD, editors. Evolution 
and dynamics of the Australian Plate. Boulder: Geological Society of America; 2003. p. 265-89.

7. Gold DP, White LT, Gunawan I, BouDagher-Fadel MK. Relative sea-level change in western New Guinea recorded by regional biostratigraphic data. Mar Pet Geol. 2017:86:1133-58.

8. Crowhurst P, Maas R, Hill K, Foster D, Fanning C. Isotopic constraints on crustal architecture and Permo-Triassic tectonics in New Guinea: possible links with eastern Australia. Aust J Earth Sci. 2004;51(1):107-22.

9. Jost BM, Webb M, White LT. The Mesozoic and Palaeozoic granitoids of north-western New Guinea. Lithos. 2018;312:223-43.

10. Webb M, White LT. Age and nature of Triassic magmatism in the Netoni Intrusive Complex, West Papua, Indonesia. J Asian Earth Sci. 2016;132:58-74

11. Holm RJ, Rosenbaum G, Richards SW. Post 8 Ma reconstruction of Papua New Guinea and Solomon Islands: microplate tectonics in a convergent plate boundary setting. Earth Sci Rev. 2016;156:66-81.

12. Holm RJ, Spandler C, Richards SW. Continental collision, orogenesis and arc magmatism of the Miocene Maramuni arc, Papua New Guinea. Gondwana Res. 2015;28(3):1117-36.

13. White LT, Hall R, Gunawan I, Kohn B. Tectonic mode switches recorded at the northern edge of the Australian Plate during the Pliocene and Pleistocene. Tectonics. 2019;38(1):281-306.

14. Webb M, White LT, Jost BM, Tiranda H, BouDagher-Fadel M. The history of Cenozoic magmatism and collision in NW New Guinea-New insights into the tectonic evolution of the northernmost margin of the Australian Plate. Gondwana Res. 2020;82:12-38.

15. Webb M, White LT, Jost BM, Tiranda H. The Tamrau Block of NW New Guinea records late Miocene-Pliocene collision at the northern tip of the Australian Plate. J Asian Earth Sci. 2019;179:238-60.

16. Sutriyono E, O'Sullivan PB, Hill KC. Thermochronology and tectonics of the Bird's Head Region, Irian Jaya: apatite fission track constraints. In: International Conference on Petroleum Systems of SE Asia and Australasia; 1997. p. 285-99.

17. Kendrick RD, Hill KC, Parris K, Saefudin I, O'Sullivan PB. Timing and style of Neogene regional deformation in the Irian Jaya Fold Belt, Indonesia. In: Proceedings Indonesian Petroleum Association; 1995. p. 249-62.

18. Hill K, Raza A. Arc-continent collision in Papua Guinea: constraints from fission track thermochronology. Tectonics. 1999;18:950-66.

19. Bailly V, Pubellier M, Ringenbach J-C, De Sigoyer J, Sapin F. Deformation zone 'jumps' in a young convergent setting; the Lengguru fold-andthrust belt, New Guinea Island. Lithos. 2009;113(1-2):306-17.

20. François C, de Sigoyer J, Pubellier M, Bailly V, Cocherie A, Ringenbach J-C. Short-lived subduction and exhumation in Western Papua (Wandamen peninsula): co-existence of HP and HT metamorphic rocks in a young geodynamic setting. Lithos. 2016;266:44-63.

21. Lam AW, Gueuning M, Kindler C, Van Dam M, Alvarez N, Panjaitan R, Shaverdo H, White LT, Roderick GK, Balke M. Phylogeography and population genomics of a lotic water beetle across a complex tropical landscape. Mol Ecol. 2018;27(16):3346-56.

22. Bocek M, Bocak $L$. The origins and dispersal history of the trichaline netwinged beetles in Southeast Asia, Wallacea, New Guinea and Australia. Zool J Linn Soc. 2019;185(4):1079-94.

23. Cozzarolo C-S, Balke M, Buerki S, Arrigo N, Pitteloud C, Gueuning M, Salamin N, Sartori M, Alvarez N. Biogeography and ecological diversifcation of a Mayfly Clade in New Guinea. Front Ecol Evol. 2019;7:233.

24. Georges A, Zhang X, Unmack P, Reid BN, Le M, McCord WP. Contemporary genetic structure of an endemic freshwater turtle reflects Miocene orogenesis of New Guinea. Biol J Lin Soc. 2014;111(1):192-208.

25. Irestedt M, Batalha-Filho H, Roselaar CS, Christidis L, Ericson PGP. Contrasting phylogeographic signatures in two Australo-Papuan bowerbird species complexes (Aves: Ailuroedus). Zool Scr. 2016;45(4):365-79.

26. Janda M, Matos-Maraví P, Borovanska M, Zima J, Youngerman E, Pierce NE. Phylogeny and population genetic structure of the ant genus Acropyga (Hymenoptera: Formicidae) in Papua New Guinea. Invertebr Syst. 2016;30(1):28-40.

27. Jønsson KA, Fabre PH, Ricklefs RE, Fjeldsa J. Major global radiation of corvoid birds originated in the proto-Papuan archipelago. Proc Natl Acad Sci USA. 2011;108(6):2328-33.

28. Kalkman VJ, Dijkstra K-DB, Dow RA, Stokvis FR, van Tol J. Out of Australia: the Argiolestidae reveal the Melanesian Arc System and East Papua Composite Terrane as possible ancient dispersal routes to the
Indo-Australian Archipelago (Odonata: Argiolestidae). Int J Odonatol. 2018;21(1):1-14.

29. Moyle RG, Oliveros CH, Andersen MJ, Hosner PA, Benz BW, Manthey JD, Travers SL, Brown RM, Faircloth BC. Tectonic collision and uplift of Wallacea triggered the global songbird radiation. Nat Commun. 2016;7:12709

30. Natusch DJ, Esquerre D, Lyons JA, Hamidy A, Lemmon AR, Lemmon EM, Riyanto A, Keogh JS, Donnellan S. Species delimitation and systematics of the green pythons (Morelia viridis complex) of Melanesia and Australia. Mol Phylogenet Evol. 2020;142:106640.

31. Oliver LA, Rittmeyer EN, Kraus F, Richards SJ, Austin CC. Phylogeny and phylogeography of Mantophryne (Anura: Microhylidae) reveals cryptic diversity in New Guinea. Mol Phylogenet Evol. 2013;67(3):600-7.

32. Oliver PM, lannella A, Richards SJ, Lee MS. Mountain colonisation, miniaturisation and ecological evolution in a radiation of direct-developing New Guinea Frogs (Choerophryne, Microhylidae). PeerJ. 2017;5:e3077.

33. Tallowin OJS, Tamar K, Meiri S, Allison A, Kraus F, Richards SJ, Oliver PM. Early insularity and subsequent mountain uplift were complementary drivers of diversification in a Melanesian lizard radiation (Gekkonidae: Cyrtodactylus). Mol Phylogenet Evol. 2018;125:29-39.

34. Unmack PJ, Allen GR, Johnson JB. Phylogeny and biogeography of rainbowfishes (Melanotaeniidae) from Australia and New Guinea. Mol Phylogenet Evol. 2013;67(1):15-27.

35. Liebherr JK. Revision of Dobodura Darlington (Coleoptera: Carabidae: Odacanthini): diversification on accreted terranes of northern New Guinea. Tijdschrift voor Entomologie. 2017;160(1):1-23.

36. Eldridge MD, Potter S, Helgen KM, Sinaga MH, Aplin KP, Flannery TF, Johnson RN. Phylogenetic analysis of the tree-kangaroos (Dendrolagus) reveals multiple divergent lineages within New Guinea. Mol Phylogenet Evol. 2018;127:589-99.

37. Todd EV, Blair D, Georges A, Lukoschek V, Jerry DR, Gillman LN. A biogeographical history and timeline for the evolution of Australian snapping turtles (Elseya: Chelidae) in Australia and New Guinea. J Biogeogr. 2014;41(5):905-18.

38. Cibois A, Thibault JC, Bonillo C, Filardi CE, Watling D, Pasquet E. Phylogeny and biogeography of the fruit doves (Aves: Columbidae). Mol Phylogenet Evol. 2014;70:442-53.

39. Heads M. Birds of paradise, vicariance biogeography and terrane tectonics in New Guinea. J Biogeogr. 2002a;29(2):261-83.

40. Schweizer M, Wright TF, Penalba JV, Schirtzinger EE, Joseph L. Molecular phylogenetics suggests a New Guinean origin and frequent episodes of founder-event speciation in the nectarivorous lories and lorikeets (Aves: Psittaciformes). Mol Phylogenet Evol. 2015;90:34-48.

41. Toussaint EFA, Hall R, Monaghan MT, Sagata K, Ibalim S, Shaverdo HV, Vogler AP, Pons J, Balke M. The towering orogeny of New Guinea as a trigger for arthropod megadiversity. Nat Commun. 2014;5:4001.

42. Shee ZQ, Frodin DG, Camara-Leret R, Pokorny L. Reconstructing the complex evolutionary history of the Papuasian Schefflera radiation through herbariomics. Front Plant Sci. 2020;11:258.

43. Aggerbeck M, Fjeldså J, Christidis L, Fabre PH, Jønsson KA. Resolving deep lineage divergences in core corvoid passerine birds supports a proto-Papuan island origin. Mol Phylogenet Evol. 2014;70:272-85.

44. Oliver PM, Brown RM, Kraus F, Rittmeyer E, Travers SL, Siler CD. Lizards of the lost arcs: mid-Cenozoic diversification, persistence and ecological marginalization in the West Pacific. Proc R Soc B. 2018. https://doi.org/ 10.1098/rspb.2017.1760.

45. Rivera JA, Kraus F, Allison A, Butler MA. Molecular phylogenetics and dating of the problematic New Guinea microhylid frogs (Amphibia: Anura) reveals elevated speciation rates and need for taxonomic reclassification. Mol Phylogenet Evol. 2017;112:1-11.

46. Toussaint EFA, Hendrich L, Shaverdo H, Balke M. Mosaic patterns of diversification dynamics following the colonization of Melanesian islands. Sci Rep. 2015;5:16016.

47. Bruxaux J, Gabrielli M, Ashari H, Prys-Jones R, Joseph L, Milá B, Besnard $G$, Thébaud C. Recovering the evolutionary history of crowned pigeons (Columbidae: Goura): implications for the biogeography and conservation of New Guinean lowland birds. Mol Phylogenet Evol. 2018:120:248-58

48. Tallowin OJS, Meiri S, Donnellan SC, Richards SJ, Austin CC, Oliver PM. The other side of the Sahulian coin: biogeography and 
evolution of Melanesian forest dragons (Agamidae). Biol J Lin Soc. 2020;129(1):99-113.

49. De Boer A, Duffels J. Historical biogeography of the cicadas of Wallacea, New Guinea and the West Pacific: a geotectonic explanation. Palaeogeogr Palaeoclimatol Palaeoecol. 1996;124(1-2):153-77.

50. Polhemus D, Polhemus JT. Two new genera and thirty new species of Microveliinae (Heteroptera: Veliidae) from the East Papua Composite Terrane, far eastern New Guinea. Tijdschrift voor Entomologie. 2004:147(2):113-89.

51. Polhemus DA, Polhemus JT. Assembling New Guinea: 40 million years of island arc accretion as indicated by the distributions of aquatic Heteroptera (Insecta). In: Hall R, Holloway JD, editors. Biogeography and geological evolution of SE Asia. Leiden: Backhuys; 1998. p. 327-40.

52. Heads M. Regional patterns of biodiversity in New Guinea animals. J Biogeogr. 2002b;29:285-94.

53. Davies H, Jaques A. Emplacement of ophiolite in Papua New Guinea. Geol Soc Lond Spec Publ. 1984;13(1):341-9.

54. Charlton T, Hall R, Partoyo E. The geology and tectonic evolution of Waigeo Island, NE Indonesia. J SE Asian Earth Sci. 1991;6(3-4):289-97.

55. APC. Geological results of petroleum exploration in Western Papua, 1937-1961. J Geol Soc Aust. 1961;8(1):1-133.

56. Davies H, Winn R, KenGemar P. Evolution of the Papuan Basin-a view from the orogen. In: Third PNG Petroleum Convention: 1996; Port Moresby Papua New Guinea (PNG) Petroleum Convention Proceedings: $1-10$.

57. Pieters P, Pigram C, Trail D, Dow D, Ratman N, Sukamto R. The stratigraphy of western Irian Jaya. Bull Geol Res Dev Centre. 1983;8:14-48,

58. Heads M. Passive uplift of plant and animal populations during mountain-building. Cladistics. 2019;35(5):550-72.

59. Balke M, Wewalka G, Alarie Y, Ribera I. Molecular phylogeny of Pacific Island Colymbetinae: radiation of New Caledonian and Fijian species (Coleoptera, Dytiscidae). Zoolog Scr. 2007;36(2):173-200.

60. Lam A, Toussaint EFA, Kindler C, Van Dam MH, Panjaitan R, Roderick GK, Balke M. Stream flow alone does not predict population structure of diving beetles across complex tropical landscapes. Mol Ecol. 2018;27(17):3541-54.

61. Shaverdo H, Surbakti S, Warikar EL, Sagata K, Balke M. Nine new species groups, 15 new species, and one new subspecies of New Guinea diving beetles of the genus Exocelina Broun, 1886 (Coleoptera, Dytiscidae, Copelatinae). Zookeys. 2019;878:73-143.

62. Shaverdo H, Balke M. A new species of the Exocelina ekari group and new faunistic data on 12 species of Exocelina BROUN, 1886 from New Guinea. Koleopterologische Rundschau. 2019;89:1-10.

63. Balke M, Ribera I. A subterranean species of Exocelina diving beetle from the Malay Peninsula filling a 4,000 km distribution gap between Melanesia and southern China. Subterr Biol. 2020;34:25-37.

64. Shaverdo H, Panjaitan R, Balke M. A new, widely distributed species of the Exocelina ekari-group from West Papua (Coleoptera, Dytiscidae, Copelatinae). Zookeys. 2016;554:69-85.

65. Balke M, Ribera I, Vogler AP. MtDNA phylogeny and biogeography of Copelatinae, a highly diverse group of tropical diving beetles (Dytiscidae). Mol Phylogenet Evol. 2004;32(3):866-80.

66. Désamore A, Laenen B, Miller KB, Bergsten J. Early burst in body size evolution is uncoupled from species diversification in diving beetles (Dytiscidae). Mol Ecol. 2018;27(4):979-93.

67. Louca S, Pennell MW. Extant timetrees are consistent with a myriad of diversification histories. Nature. 2020;580(7804):502-5.

68. Duffels J, Turner H. Cladistic analysis and biogeography of the cicadas of the Indo-Pacific subtribe Cosmopsaltriina (Hemiptera: Cicadoidea: Cicadidae). Syst Entomol. 2002;27(2):235-61.

69. Rahbek C, Borregaard MK, Antonelli A, Colwell RK, Holt BG, NoguesBravo D, Rasmussen CMO, Richardson K, Rosing MT, Whittaker RJ, et al. Building mountain biodiversity: geological and evolutionary processes. Science. 2019;365(6458):1114-9.

70. Espeland M, Johanson KA, Hovmöller R. Early Xanthochorema (Trichoptera, Insecta) radiations in New Caledonia originated on ultrabasic rocks. Mol Phylogenet Evol. 2008;48(3):904-17.

71. Isnard S, L'Huillier L, Rigault F, Jaffré T. How did the ultramafic soils shape the flora of the New Caledonian hotspot? Plant Soil. 2016;403(1-2):53-76.
72. Slavenko A, Tamar K, Tallowin OJS, Allison A, Kraus F, Carranza S, Meiri S. Cryptic diversity and non-adaptive radiation of montane New Guinea skinks (Papuascincus; Scincidae). Mol Phylogenet Evol. 2020;146:106749.

73. Shaverdo H, Sumoked B, Balke M. Descriptions of two new species and one new subspecies from the Exocelina okbapensis-group, and notes on the E. aipo-group (Coleoptera, Dytiscidae, Copelatinae). ZooKeys. 2017;715:17-37.

74. Toussaint EFA, Sagata K, Surbakti S, Hendrich L, Balke M. Australasian sky islands act as a diversity pump facilitating peripheral speciation and complex reversal from narrow endemic to widespread ecological supertramp. Ecol Evol. 2013;3(4):1031-49.

75. Cloos M, Sapiie B, van Ufford AQ, Weiland RJ, Warren PQ, McMahon TP. Collisional delamination in New Guinea: the geotectonics of subducting slab breakoff. Geol Soc Am Spec Pap. 2005;400:1-51.

76. Riedel A, Daawia D, Balke M. Deep cox1 divergence and hyperdiversity of Trigonopterus weevils in a New Guinea mountain range (Coleoptera, Curculionidae). Zoolog Scr. 2010;39(1):63-74.

77. Pigram CJ, Davies HL. Terrranes and the accretion history of the New Guinea orogen. BMR J Aust Geol Geophys. 1987;10:193-211.

78. Monnier C, Girardeau J, Pubellier M, Polvé M, Permana H, Bellon H. Petrology and geochemistry of the Cyclops ophiolites (Irian Jaya, East Indonesia): consequences for the Cenozoic evolution of the north Australian margin. Mineral Petrol. 1999;65(1-2):1-28.

79. Weiland R. Emplacement of the Irian Ophiolite and unroofing of the Ruffaer Metamorphic Belt of Irian Jaya, Indonesia. PhD thesis. University of Texas at Austin; 1999.

80. Daczko NR, Caffi P, Mann P. Structural evolution of the Dayman dome metamorphic core complex, eastern Papua New Guinea. Bulletin. 2011; 123(11):2335-51.

81. Österle J, Little T, Seward D, Stockli D, Gamble J. The petrology, geochronology and tectono-magmatic setting of igneous rocks in the Suckling-Dayman metamorphic core complex, Papua New Guinea. Gondwana Res. 2020;83:390-414.

82. van Ufford AQ, Cloos M. Cenozoic tectonics of New Guinea. AAPG Bull. 2005;89(1):119-40.

83. Mahoney L, Mclaren S, Hill K, Kohn B, Gallagher K, Norvick M. Late Cretaceous to Oligocene burial and collision in western Papua New Guinea: indications from low-temperature thermochronology and thermal modelling. Tectonophysics. 2019;752:81-112.

84. Haq B, Hardenbol J, Vail P. The new chronostratigraphic basis of Cenozoic and Mesozoic sea level cycles. Spec Publ Cushman Found Foraminiferal Res. 1987;24:7-13.

85. Haq BU. Cretaceous eustasy revisited. Glob Planet Change. 2014;113:44-58.

86. Visser WA, Hermes JJ. Geological results of the exploration for oil in Netherlands New Guinea. s'Gravenhage: Staatsdrukkerij-en Uitgeverijbedrijf; 1962.

87. Nannotax3 website, International Nannoplankton Association [www/ mikrotax.org/Nannotax3]

88. Bird P. An updated digital model of plate boundaries. Geochem Geophys Geosyst. 2003;4(3):1-52.

89. Amante C, Eakins B. ETOPO1 1 Arc-minute global relief model: procedures, data sources and analysis. NOAA Technical Memorandum NESDIS NGDC-24, National Geophysical Data Center, NOAA; 2009. 10:V5C8276M.

90. Shaverdo H, Surbakti S, Sumoked B, Balke M. Three new species of Exocelina Broun, 1886 from the southern slopes of the New Guinea Central Range, with introduction of the Exocelina skalei group (Coleoptera, Dytiscidae, Copelatinae). ZooKeys. 2020;1007:129.

91. Shaverdo H, Surbakti S, Sumoked B, Balke M. Seven new species of the Exocelina ekari group from New Guinea central and coastal mountains (Coleoptera, Dytiscidae, Copelatinae). ZooKeys. 2021; in press.

92. Edgar RC. MUSCLE: multiple sequence alignment with high accuracy and high throughput. Nucleic Acids Res. 2004;32(5):1792-7.

93. Miller KB, Bergsten J. The phylogeny and classification of predaceous diving beetles. In: Ecology, systematics, and the natural history of predaceous diving beetles (Coleoptera: Dytiscidae). Dordrecht: Springer; 2014. p. 49-172. 
94. Nguyen L-T, Schmidt HA, Von Haeseler A, Minh BQ. IQ-TREE: a fast and effective stochastic algorithm for estimating maximum-likelihood phylogenies. Mol Biol Evol. 2015;32(1):268-74.

95. Kalyaanamoorthy S, Minh BQ, Wong TK, von Haeseler A, Jermiin LS. ModelFinder: fast model selection for accurate phylogenetic estimates. Nat Methods. 2017;14(6):587.

96. Minh BQ, Nguyen MAT, von Haeseler A. Ultrafast approximation for phylogenetic bootstrap. Mol Biol Evol. 2013;30(5):1188-95.

97. Hoang DT, Chernomor O, Von Haeseler A, Minh BQ, Vinh LS. UFBoot2: improving the ultrafast bootstrap approximation. Mol Biol Evol. 2018;35(2):518-22.

98. Guindon S, Dufayard J-F, Lefort V, Anisimova M, Hordijk W, Gascuel O. New algorithms and methods to estimate maximum-likelihood phylogenies: assessing the performance of PhyML 3.0. Syst Biol. 2010;59(3):307-21.

99. Suchard MA, Lemey P, Baele G, Ayres DL, Drummond AJ, Rambaut A. Bayesian phylogenetic and phylodynamic data integration using BEAST 1.10. Virus Evol. 2018;4(1):vey016.

100. Yu Y, Blair C, He X. RASP 4: ancestral state reconstruction tool for multiple genes and characters. Mol Biol Evol. 2020;37(2):604-6.

101. Baldwin SL, Monteleone BD, Webb LE, Fitzgerald PG, Grove M, Hill EJ. Pliocene eclogite exhumation at plate tectonic rates in eastern Papua New Guinea. Nature. 2004;431(7006):263-7.
102. Polhemus DA, Allen GR. Freshwater biogeography of Papua. In: Ecology of Papua part 1, vol. VI. New York: Tuttle Publishing; 2007. p. 207-45.

103. Rabosky DL. Automatic detection of key innovations, rate shifts, and diversity-dependence on phylogenetic trees. PLOS ONE. 2014;9(2):e89543.

104. Rabosky DL, Grundler M, Anderson C, Title P, Shi JJ, Brown JW, Huang H, Larson JG. BAMM tools: an R package for the analysis of evolutionary dynamics on phylogenetic trees. Methods Ecol Evol. 2014;5(7):701-7.

105. Morlon H, Lewitus E, Condamine FL, Manceau M, Clavel J, Drury J. RPANDA: an R package for macroevolutionary analyses on phylogenetic trees. Methods Ecol Evol. 2016;7(5):589-97.

106. Etienne RS, Haegeman B, Stadler T, Aze T, Pearson PN, Purvis A, Phillimore AB. Diversity-dependence brings molecular phylogenies closer to agreement with the fossil record. Proc R Soc B. 2012;279(1732):1300-9.

107. Condamine FL, Rolland J, Morlon H. Assessing the causes of diversification slowdowns: temperature-dependent and diversity-dependent models receive equivalent support. Ecol Lett. 2019;22(11):1900-12.

\section{Publisher's Note}

Springer Nature remains neutral with regard to jurisdictional claims in published maps and institutional affiliations.
Ready to submit your research? Choose BMC and benefit from:

- fast, convenient online submission

- thorough peer review by experienced researchers in your field

- rapid publication on acceptance

- support for research data, including large and complex data types

- gold Open Access which fosters wider collaboration and increased citations

- maximum visibility for your research: over $100 \mathrm{M}$ website views per year

At BMC, research is always in progress.

Learn more biomedcentral.com/submissions 